\title{
NEIGHBOURHOOD TURNOVER AND TEENAGE ATTAINMENT
}

\author{
Stephen Gibbons \\ London School of Economics
}

\section{Felix Weinhardt}

German Institute for Economic Research (DIW), Berlin

\author{
Olmo Silva \\ London School of Economics
}

\begin{abstract}
Theories about neighbours' influence on children's education that are based on social capital, cohesion, and disorganisation stress the importance of neighbourhood stability. This is because stability is regarded as necessary for building strong ties and friendships, which in turn affect educational outcomes. However, amongst the vast number of studies on the effect of neighbours on a child's education, none has tested whether neighbourhood stability matters. We fill this gap by estimating the causal effect of residential turnover on student test score gains. Estimation is based on administrative data on four cohorts of secondary school students in England, allowing us to control for pupil-level, neighbourhood-level, and school-by-cohort level unobservables and for changes in neighbourhood composition driven by students' residential mobility. We show that a high turnover of same-school-grade students reduces value added for teenagers who stay in their neighbourhood, although turnover of other age groups does not matter. These results coupled with auxiliary findings based on survey data suggest that neighbours' turnover damages education through the disruption of local ties and friendships, highlighting a so-far undiscovered spillover of mobility. (JEL: C21; I20, R23)
\end{abstract}

\section{Introduction}

Geographical mobility is generally considered essential for the functioning of efficient markets. Amongst other things, geographic mobility of people offers opportunities

\footnotetext{
The editor in charge of this paper was M. Daniele Paserman.
}

Acknowledgments: We would like to thank Tony Champions, Camille Hemet, Larry Katz, Daniele Paserman (the Editor), Steve Rivkin, four anonymous referees, and participants at the CEP Labour Market Workshop, NIESR Seminar (London), the SERC Annual Conference 2013, SOLE Annual Meetings 2014, the Tinbergen Institute (Amsterdam), the University of Alicante, the University of York and the III Workshop in Urban Economics (Barcelona) for helpful comments and suggestions. Weinhardt acknowledges ESRC funding (ES/J003867/1). We are responsible for any remaining errors or omissions. The authors are Research Fellows at IZA.

E-mail: s.gibbons@1se.ac.uk (Gibbons); o.silva@1se.ac.uk (Silva);

felix.weinhardt@hu-berlin.de (Weinhardt) 
for individual investment in human capital, extends the pool of offers available to job seekers, and allows adjustment to geographical changes in economic structure (Sjaastad 1962; Jovanovic 1979; Greenwood 1997; Partridge et al. 2012). ${ }^{1}$ Similarly, mobility promotes the efficient provision of local public services through spatial competition (Tiebout 1956). However, the movement of people can, at the same time as generating benefits, impose considerable costs in terms of human capital development. These costs might spill over on other members of a person's family, on their friends, their neighbours or their community.

Our research focuses on identifying this spillover effect of mobility by studying to what extent the educational achievement of teenagers is affected by turnover in the neighbourhood-and in particular by the turnover of neighbours of the same age. Given its focus on residential mobility, our work clearly relates and contributes to the extensive economic literature on neighbourhood effects. Existing empirical work has focussed on the way individuals are affected by a "black-box" of neighbourhood differences (e.g., Kling et al. 2005, 2007; Sanbonmatsu et al. 2006; Weinhardt 2014; Chetty et al. 2015) or by the composition of the group to which individuals belong (e.g., Gibbons et al. 2013). This literature finds little evidence that neighbours have much influence on academic achievement. However, the specific role of the rate at which people enter and leave the neighbourhood has been ignored. Theoretical work in the economics of social interactions has similarly neglected this potentially important aspect of the neighbourhood environment (e.g., Durlauf 1996; Manski 2000). This is an important omission given the explicit role of community stability in many sociological theories that motivated much of the interest in neighbourhood effects. Our study fills this gap and estimates the negative spillover effect of neighbours' turnover on the attainment of pupils who do not move-while accounting for any possible effects of changes in neighbourhood composition brought around by students' mobility. By focussing on the external effects of neighbour turnover per se, and abstracting from the impact of changes in composition, we draw attention to important - but as yet ignored-questions about the social costs of residential mobility.

Sutherland (1934) was amongst the first to suggest that higher levels of neighbourhood turnover break down strong ties amongst local residents, trigger "social disorganization" and increase criminality. His insights stimulated a long line of theoretical and empirical work in sociology (e.g., Shaw and Mackay 1969; Sampson and Byron Groves 1989). Within the urban study field, Jacobs (1961) was prominent in suggesting that neighbourhood turbulence can negatively affect children's well-being and learning. Similarly, residential mobility features as an important barrier to the accumulation of personal human capital in theories of "social capital" (the antithesis of social disorganisation), because the "social relations that constitute social capital

1. Very few studies have shed light on potential negative effects from high levels of turnover (e.g., Huckman and Barro 2005 for hospitals), with more work concentrated on the determinants of high mobility rates (Kaplan and Minton 2006; Gentry and Hubbard 2002). 
are broken at each move" (Coleman 1988, p. S113). ${ }^{2}$ This frequent fracturing in social relations in high mobility neighbourhoods presumably affects everyone in the community, not just those who move, leading to social as well as private costs.

In order to investigate the empirical relevance of these theories, we use administrative data on the educational record of over 1.5 million school children in England tracking the progress of four age cohorts as they transit from the end of primary (age 11) to the middle of secondary schooling (age 14). We define an age cohort as the group of students in the same school grade in a given academic year. Students in England almost never repeat or skip a year of study, so pupils in the same school grade are almost always born between the beginning of September in one year and the end of August the following year (i.e., they are less than a year apart). Our data contain information on pupils' test scores, schools attended at different grades, background characteristics, and detailed information on place of residence, which allows us to calculate changes in home address. We use these data to construct measures of the residential turnover of same-grade students based on inflows and outflows at a small neighbourhood level. We then estimate the effect of this turnover on the educational progress of students who are in the same grade as the movers but who do not move from the neighbourhood between ages 11 and 14 (educational progress is measured in percentile test score gains). By limiting our main estimation sample to students who stay in the same neighbourhood we identify the effect of movers on stayers - that is, the effect of spillovers associated with turnover-while by-passing the problem of identifying the effect of own moves. ${ }^{3}$ In order to identify the causal impact of neighbours' turnover, we exploit the dimensionality and geographical detail of our data and use a fixed effects regression-based empirical strategy that allows us to control for individual unobservables, small-area neighbourhood fixed effects, and school-by-cohort shocks that might affect turnover rates and student achievement.

Even in highly saturated specifications with a full range of fixed effects and covariates, we find that pupils' educational progress between age 11 and 14 is reduced by the turnover of same-grade students moving in and out of the neighbourhood. A one standard deviation (s.d.) increase in annual turnover (about 13\%) causes a $0.3 \%$ $0.4 \%$ of a standard deviation reduction in test score gains between ages 11 and 14 . These effects are subtle, lying somewhere between the zero effects usually found from neighbours' interactions and the small effects from school peers documented in carefully executed studies.

This estimated effect is not due to turnover in schools or other school-specific factors that have common effects on all students in a school-cohort group, since we control for these very flexibly by including school-by-cohort fixed effects. In England, it is feasible to identify neighbourhood effects conditional on school effects because there

2. More recently, the field of social psychology has also explored the importance of turnover for performance and learning. See, for example, Levin and Choi (2004) and Argote et al. (2006).

3. We check for possible sample selection issues by replicating our analysis on the full sample of movers and stayers, but assigning movers the turnover rate they would have experienced had they not moved. For the movers, we also control for direct effects of mobility. 
is not a one-to-one mapping between place of residence and attended school: pupils living in the same neighbourhood typically attend two to three different secondary schools, and schools attract pupils from more than 60 neighbourhoods. Similarly, our results are not driven by changes in neighbourhood composition, which we carefully control for and have shown to have precisely estimated zero impact in previous work (Gibbons et al. 2013). Finally, our findings are not easily explained by unobserved neighbourhood factors simultaneously affecting mobility and attainment, because our specifications control for small neighbourhood fixed effects and estimation lives off the within-neighbourhood, cohort-on-cohort variation in turnover, and test scores-which we show to be uncorrelated with an extensive set of neighbourhood characteristics.

We also shed light on potential mechanisms for these effects of turnover. Our results show that the educational progress of secondary school pupils in a given cohort is unaffected by the turnover of primary school children, younger cohorts, older cohorts, or adults (45-64-year olds). It is instead only affected by the residential mobility of same-grade pupils. This finding suggests a specific role for social interactions between neighbours of similar age, potentially because they know each other since they go to school together or are otherwise linked through mutual friends of the same age across the local school network. We thus hypothesize that our findings could be attributed to the disruption of social ties and friendship networks amongst same-grade pupils caused by members of the group leaving and breaking existing links, as well as by the time and effort needed to adapt to and get to know new arrivals. ${ }^{4}$

Using additional survey data for approximately 10,000 secondary school children, we find evidence consistent with this hypothesis: pupils living in neighbourhoods with high levels of turnover are less socially connected - for example, they tend to visit their friends' homes less frequently, are more likely to be excluded from groups of peers, and spend more of their free time "hanging around" the house. A large sociological and psychological literature stresses the importance of friends and stable social circles for students' academic performance (Wentzel 1993; Roseth et al. 2008). ${ }^{5}$ Recently, Lavy and Sand (2012) have tested these theories using data on the disruption to social relationships amongst Israeli students during the transition from primary to secondary school, whereas Calvó-Armengol et al. (2009) have documented the importance of friends for educational attainments in general. Our findings contribute to this literature by showing that high levels of neighbourhood turnover lower pupils' attainment by undermining their local connections and social capital.

Although there is some empirical work on the relationship between mobility and individual outcomes, nearly all of this evidence concerns the private costs and benefits of mobility, that is, the effects of mobility on the movers, rather than its spillovers. A number of papers have found lower social capital amongst those

4. See Levine and Hogg (2010) for a survey of the literature on the possible negative effects of leavers as well as joiners of social groups and close networks.

5. In one of the most cited sociological articles of all time, Granovetter (1973) argues that dyadic ties between two individuals are strengthened when they are nested within the context of a group of individuals who share friendship bonds. Mobility that weakens bilateral relations also weakens the strength of relationships in the group as a whole. 
undertaking more frequent residential moves (e.g., Pribesh and Downey 1999; Pettit and McLanahan 2003). Home ownership - a factor closely linked to lower rates of residential turnover-has also been associated with greater social capital (DiPasquale and Glaeser 1999; Hilber 2010). There is also evidence showing that children who move frequently (changing residence and/or school) have worse outcomes on various dimensions_-including educational attainment (Hagan et al. 1996; Coleman 1988; Hanushek et al. 2004; Schwartz et al. 2009). Work aimed at identifying the spillover effect of turnover is however almost nonexistent. A small literature has developed on the spillover effects of turnover of children in schools, finding that higher rates of mobility have significant adverse effects on other children's achievement, both in the United States (Hanushek et al. 2004) and England (Gibbons and Telhaj 2011). Aaronson (2000) briefly discusses the influence of neighbours' mobility, although his paper is mostly about the role of own mobility in explaining the association between home ownership and educational attainment, and thus its methods are not designed to identify the causal impacts of neighbours' mobility. As far as we are aware, ours is the first work to look explicitly at spillovers from neighbours' mobility on the educational attainment of nonmovers.

The rest of the paper is structured as follows. Section 2 describes our data sources and the general institutional context. Section 3 sets out the empirical specification and the identifying assumptions. Sections 4-5 describe the results and Section 6 concludes.

\section{Context and Data}

Our analysis is based on state-school students in England during the first three years of their secondary education. Compulsory primary education in England runs from age 5 (grade 0 ) to age 11 (grade 6), whereas compulsory secondary education runs from age 12 (grade 7) through to age 16 (grade 11). During our study period, students took a series of compulsory national assessments at age 7 (grade 2/Key Stage 1/KS1), age 11 (grade 6/Key Stage 2/KS2), and age 14 (grade 9/Key Stage 3/KS3). ${ }^{6}$ At age 16, students took their end-of-compulsory education qualifications (General Certificate of Secondary Educations (GCSEs) and equivalents). However, due to data limitations, in our study we do not analyse students beyond KS3.

School admission is closely, but not exactly, linked to place of residence. The exact details vary by school and school district (Local Education Authority, LEA), and have changed over time. ${ }^{7}$ However, the general picture for the period of our analysis was that admission to state schools at both the primary and secondary phase was based on principles of parental choice, although in practice parents' freedom to choose is

6. Years of progress through schooling are not referred to as "grades" in England, but we use this terminology as it simplifies discussion and makes it comparable with the international literature.

7. There are 150 LEAs in England. At the time of our analysis, these were responsible for the strategic management of education services, including planning the supply of school places and allocating central funding to schools. 
constrained by the fact that popular schools become over-subscribed. When this occurs, various criteria are used to prioritise students, usually favouring those who live nearby, those with special educational needs, or those with siblings in the school. Certain types of schools can prioritise students according to other criteria-for example, religion (faith schools) or specific aptitudes (music and other specialist schools). A small proportion of state secondary schools select on prior achievement (grammar schools), but students in these schools are excluded from our analysis. As result of these features of the admissions system, there is not a one-to-one link between place of residence and school attended, and neighbouring children attend many different schools. These details are important for our analysis of the effects of residential turnover amongst same-grade peers as it means that high residential turnover does not necessarily imply high school turnover, and vice versa.

Our main data source is administrative information on students in England at the beginning of their secondary school careers taken from the National Pupil Database (NPD). We use records from the NPD for approximately 1.5 million students belonging to four grade 9 cohorts taking their KS3 assessments in 2005, 2006, 2007, and 2008, sitting for their KS2 tests in grade 6 in 2002, 2003, 2004, and 2005, and taking KS1 exams in grade 2 in 1998, 1999, 2000, and 2001. The NPD provides various pieces of information on students, including test scores in English, Mathematics and Science at KS2 and KS3; assessments in English and Maths at KS1; background characteristics, such as gender, eligibility for free meals and ethnicity; schools attended and their characteristics; and postcode of residence. Using postcodes, we assign pupils to census output areas (OAs) that constitute small neighbourhoods hosting on average 125 households and approximately 5 children of the same age. We use OAs to define students' residential neighbourhoods. In some robustness checks we look at alternative neighbourhood definitions.

Our main estimation focuses on the subset of students who stay in the same residential neighbourhood over the years between their KS2 tests in grade 6 and their $\mathrm{KS} 3$ tests in grade 9. More precisely, the stayers are defined as students whose home address is recorded as being the same in grade 6 , grade 7 , grade 8 , and grade 9. For the remaining students who move over the grade 6 to 9 period, we still have complete information on place of residence, characteristics, and test scores. We use these students to construct neighbourhood turnover rates specific to each cohort, as well as changes in the neighbourhood composition between grade 6 and 9 driven by this residential mobility.

Neighbourhood-by-cohort turnover rates are built from the inflow and outflow rates of same-grade students in a given cohort (a cohort being defined as students in the same grade in a given academic year), within each student's residential census OA and averaged over the three one-year intervals corresponding to grades 6-7, 7-8, and 8-9. Formally, we measure turnover as $m o b_{n c}=1 / 3 \sum_{t=1}^{t=3}\left(i n_{n c t}+o u t_{n c t}\right) /$ stock $_{n c t}$, where $i n_{n c t}$ is the inflow of same-grade students to OA $n$ during one of these three one-year periods $t$ for cohort $c$, out ${ }_{n c t}$ is the outflow of same-grade children from OA $n$ over the same period for cohort $c$, and stock $_{n c t}$ is the number of same-grade students belonging to cohort $c$ at the beginning of each of the three one-year periods. The 
advantages of our turnover measure over using separate entry and exit rates are that: (a) interpreting the effects from entry rates conditional on exit rates and vice versa is problematic, given that these are not separately identified from students' population growth/decline effects; (b) turnover is not mechanically correlated with neighbourhood growth/decline, since a high turnover rate is in principle equally likely to correspond to stable, growing, or declining neighbourhoods; and (c) entry and exit rates are highly correlated so including them in the same regression is problematic. ${ }^{8}$ However, in some specifications, we explore the effects of entry and exit rates separately.

Following the same approach, we also construct analogous turnover measures for various other age groups, which we use as control variables and to study the role of similarity between the age of movers and stayers. In particular, we construct turnover of primary school age children, turnover of children one grade above our main cohorts, and turnover of children one grade below our main cohorts (grades 3-6, grades 5-8, and grades 7-10, respectively, at the time when students in our cohorts are in grades 6-9).

Note that we restrict the sample to individuals with nonmissing information in all periods of our investigation, so that variation in neighbourhood mobility and neighbourhood characteristics is not driven by students dropping in and out of our sample, but only by residential changes. Given the quality of the data, this restriction is virtually inconsequential in terms of sample size and representativeness.

In the last part of our analysis, we also make use of the Longitudinal Study of Young People in England (LSYPE), which samples approximately 14,000 students aged 14 in 2004 in 800 schools, and follows them as they progress through their secondary education up to age 16 and beyond. This set of pupils belongs to a cohort that is one-year older than the first cohort included in our main sample. Most of the information available for our main sample is available for the LSYPE children too, except for age-7 KS1 test scores. Information on place of residence is only available for grades 7, 8, and 9 (ages 12-14), so for this cohort we calculate neighbourhood turnover (and associated changes in neighbourhood composition) over the two-year interval corresponding to grades 8 and 9, rather than the three-year interval used in our main analysis.

The LSYPE survey covers students' experiences at school, at home, and in their neighbourhood, and contains a number of questions related to pupils' social ties and use of their leisure time. These questions were asked in a confidential environment to encourage students to answer truthfully. We use this information to investigate the link between neighbourhood turnover and social connectedness.

Other information on housing prices and demographic characteristics is merged in with the pupil level data using the residential postcodes and OAs. Our main dataset provides us with information on more than 1.2 million students who stay in the same

8. Empirically, we find a small, positive correlation (0.12) between neighbourhood turnover and change in the number of students living in the OA between grade 6 and grade 9 . On the other hand, the correlation between exit and entry rates is sizeable, at 0.35 , and this association remains strong and significant even when we consider the within-OA across-cohorts correlation between inflows and outflows of students. 
residential neighbourhood between ages 11 and 14, whereas the LSYPE data provide us with information on approximately 10,000 students who do not change their address between ages 12 and 14. The next section discusses the empirical specifications we use to estimate the effects of neighbourhood turnover on these students' outcomes.

\section{Empirical Specification}

The aim of our empirical work is to estimate the spillover effect of neighbourhood turnover on students' educational attainment during secondary school. Our empirical specification controls for a number of potential pupil-level, school-level and neighbourhood-level unobservables that might be correlated with pupils' outcomes and neighbourhood turnover. To formalize our discussion, we assume a simple linear educational production function in which the educational progress (i.e., "value added", measured by test score gains) between the KS2 and KS3 tests for student $i$, living in neighbourhood $n$, belonging to cohort $c$, and attending schools $s 2$ at KS2 (grade 6 ) and $s 3$ at KS3 (grade 9) depends on residential turnover in the student's home neighbourhood in the years between grade 6 and $9\left(m o b_{n c}\right)$ described in Section 2. Furthermore, pupil value added is affected by student, neighbourhood, and school characteristics that are observed in our data $\left(x_{\text {incs }}\right)$, as well as unobserved factors at the neighbourhood $\left(v_{n}\right)$, school $\left(v_{s 2}\right.$ and $v_{s 3}$ for primary and secondary, respectively), and cohort $\left(\tau_{c}\right)$ level. These are potentially correlated with neighbourhood turnover and we allow them to affect value added very flexibly through a function $f(\cdot)$. Finally, pupil value added is affect by a random error term $\left(\varepsilon_{\text {incs }}\right)$ uncorrelated with all other factors. Putting this all together, our empirical model takes the following form ${ }^{9}$ :

$$
(\mathrm{KS} 3-\mathrm{KS} 2)_{i n c s}=\operatorname{mob}_{n c} \beta+x_{i n c s}^{\prime} \lambda+f\left(v_{n}, \tau_{c}, v_{s 2}, v_{s 3}\right)+\varepsilon_{i n c s}
$$

In our main empirical application, we estimate equation (1) on the subset of students who do not move neighbourhood between grade 6 and 9 , so $n$ is fixed for a given student $i$. This restriction means that individual student's own mobility between these grades does not enter into equation (1). This allows us to focus on the spillover effects of turnover on stayers. In some extensions, we estimate equation (1) using the extended sample that includes movers. In this case, we control for students' own mobility and assign turnover based on the neighbourhood of origin since any subsequent measure of turnover is likely to be endogenous because of residential sorting.

As discussed, cohort $c$ defines a group of students that are in the same school grade in the same academic year, and each cohort is identified by the year when students took their KS3 tests in grade 9 (either 2005 or 2006 or 2007 or 2008). Since there is no grade repetition or skipping in England, these students remain in the same cohort throughout the period. In equation (1), $\mathrm{KS} 3-\mathrm{KS} 2_{i}$ is the change in individual student

9. Appendix I in the working paper version of this paper provides more details about the analytics leading to this model specification. 
test scores between Key Stage 2 and Key Stage 3. Test scores are averaged across English, mathematics and science and converted to percentiles within the national student distribution for cohort $c$. We found no difference in our results when we studied outcomes in English, mathematics and science separately.

The focus of our interest is on the estimation of $\beta$, interpreted as the expected change in students' test score gains caused by an exogenous change in neighbourhood residential turnover during the years between the two tests. The challenge to the consistent estimation of $\beta$ is that neighbourhood-cohort turnover $m o b_{n c}$ is likely to be correlated with the unobserved determinants of test score gains in $f(\cdot)$. This correlation occurs because turnover and student achievement are affected by similar unobserved factors, and because students who differ in unobservable ways will sort into high/low turnover neighbourhoods. For example, turnover could be higher in areas populated by low-income/socioeconomic groups, with higher rates of job and family separation, and a high incidence of short term rental housing. Residential sorting would imply that these factors also characterise a student's own family situation and hence have direct effects on student's achievement. Furthermore, as discussed in Section 2, England uses a system in which school choice is partially constrained by where students live in relation to schools. Therefore, turnover could also be related to local school quality (e.g., teaching quality, resources, and composition) through the school-choice process. This also implies that turnover in the neighbourhood might be correlated with turnover in schools - which has been shown to have direct effects on pupil achievement (Hanushek et al. 2004; Gibbons and Telhaj 2011). These school-related effects are potentially relevant in our context because we study the period from grade 6 to 9 , during which students move between primary and secondary school, so there is considerable school-choice related mobility.

Our identification strategy exploits the detail and size of our data-coupled with institutional features of schooling in England-to control for the unobserved factors in $f(\cdot)$ through a variety of neighbourhood, cohort, primary-, and secondary-school fixed effects. First and foremost, the data allow us to include small neighbourhood (OA) fixed effects to control for the confounding effect of $v_{n}$ because we have multiple cohorts of students. In this case identification comes from the variation in neighbourhood-by-cohort turnover between cohorts. Given the very small scale of these neighbourhoods, cohort-to-cohort variation in turnover is likely driven only by exogenous highly localised variation in individuals' decisions about neighbourhood of residence, interacting with housing availability. We support this intuition by providing an extensive set of balancing regressions showing that within-OA across-cohort variation in turnover is uncorrelated with cross-cohort changes in neighbourhood characteristics.

Furthermore, we can control for school-by-cohort fixed effects in our specifications because, as explained in Section 2, there is not a one-to-one mapping between the neighbourhood where children live and the school they attend. Pupils of the same age and living in the same OA attend, on average, two to three different secondary schools, and these schools usually attract pupils from more than 60 OAs. This institutional feature allows us to control for secondary school-by-cohort fixed effects (or even 
primary-by-secondary-by-cohort fixed effects), at the same time as controlling for neighbourhood fixed effects, thus also partialling out the cohort-specific unobserved effects of $v_{\mathrm{s} 2}$ and $v_{\mathrm{s} 3} \cdot{ }^{10}$

Conversely, it is infeasible to include individual fixed effects to directly account for the effect of individual unobservables on value added because we only observe changes in test scores once for each student (i.e., between grade 6 and 9). ${ }^{11}$ However, controlling for neighbourhood fixed effects mitigates these issues as long as the composition of the neighbourhood in terms of mean individual unobservables does not change between cohorts over our period of study. Given our focus on stayers, this assumption seems plausible. Once again, we provide evidence in support of this assumption by presenting an extensive set of balancing regressions, which show that changes between cohorts in the characteristics of the stayers are uncorrelated with neighbours' turnover.

In addition to these fixed effects, we can include a selection of conditioning variables in $x_{\text {incs }}$ in our specifications, drawn from what we observe in our data. Individual characteristics include gender, KS1 (age-7) attainments, free school meal entitlement (FSM) special education needs (SEN), and ethnicity. These characteristics are recorded in grade 6 and treated as fixed/predetermined. We account for timevarying features of the neighbourhood that relate to the cohort under analysis using a range of additional covariates in the regressions. We include changes (between grade 6 and 9) in neighbourhood-by-cohort mean student characteristics (KS1, FSM, SEN, ethnicity), where the changes in the means of these predetermined characteristics come from mobility of students in and out of the neighbourhood. We also control for the grade 6 levels of these neighbourhood-by-cohort means. This approach allows us to partial out the effect of neighbourhood initial composition and the effect of changes to composition driven by mobility-thus isolating the impact of neighbours' turnover of test score value added holding constant neighbourhood characteristics.

Further, in all specifications that include covariates, we control for the number of grade 6 students in the neighbourhood, and the change in the number of students between grade 6 and 9 . This allows us to isolate the effect of turnover while controlling for any direct impact of size of a pupil's potential network, as well as any unobservable that attracts or deters movers (and so affect net inflows).

In addition, most specifications include the neighbourhood-by-cohort turnover rate of primary school children as a covariate. This variable acts as an additional control

10. Secondary school-by-cohort effects are based on the school attended in grade 7, at the beginning of secondary education, to by-pass potential concerns with subsequent school changes being endogenous to turnover.

11. On the other hand, Appendix I in the working paper shows that focussing on pupils who do not move and estimating a value-added specification controls for time-fixed individual and neighbourhood unobserved attributes — such as "ability" and "sorting"- that affect the level of attainments. 
for neighbourhood shocks not captured by neighbourhood fixed effects and the other covariates. $^{12}$

To sum up, our identifying assumption in estimating equation (1) is that the cohortto-cohort changes in small-scale neighbourhood, cohort-specific residential turnover are uncorrelated with the unobserved determinants of student achievement, once we condition on neighbourhood, school, and cohort fixed effects, and control for a broad set of pupil and neighbourhood time-varying observables. We assess our identifying assumptions by examining the sensitivity of the estimates of $\beta$ to different combinations of these fixed effects and covariates. Moreover, we present balancing tests that show that observable neighbourhood-by-cohort and individual characteristics are uncorrelated with neighbourhood turnover once we condition on neighbourhood fixed effects. This extensive battery of tests suggests that our results are not spurious, but causally linked to pupil value added.

\section{Main Results}

\subsection{Descriptive Statistics}

Descriptive statistics for our estimation sample of residential stayers are presented in Table 1 . The main estimation sample has 1.2 million students evenly spaced over four cohorts and living in around 133,000 OAs. ${ }^{13}$ The top panel of the table summarises the individual characteristics. The percentiles of the KS2 and KS3 test scores are based on the full set of stayers and movers, and for pupils who do not move have a mean of 50 and standard deviation of 26. The value added in the full dataset has a mean of zero. The descriptive statistics in Table 1 are comparable to those in the overall sample (not tabulated) suggesting that the sample of stayers is not unrepresentative of the population. Stayers have marginally higher KS2 achievements (by 0.12 percentiles), higher KS3 achievements (by 1.22 percentiles), and a slightly higher value added (by 1.1 percentiles), which is consistent with the literature that shows that frequent moves are associated with lower educational achievements (Hanushek et al. 2004; Schwartz et al. 2009). We do not go any further here in trying to establish causality in this relationship.

Panel B presents descriptive statistics for the neighbourhoods of residence. These show that the average rate of annual turnover between grade 6 and 9 is $14.5 \%$, split between $6.4 \%$ outwards mobility, and $8.1 \%$ inwards mobility. On average, 5.3 pupils of the same age live in the same OA. Turnover amongst primary school age children from grade 3 to 6 is larger at $20.4 \%$. The fact that residential mobility is higher in

12. Our control variables also include the size of the school attended at the beginning of secondary school (in grade 7) and school-type dummies (also referring to the school attended in grade 7) when school effects are not included.

13. The total number of pupils including movers is approximately 1.5 million. This corresponds to around $95 \%$ of the total number of students in the administrative data prior to dropping observations with missing data. 
primary school years has been previously documented in the United Kingdom (see Machin et al. 2006). The table also shows the change in neighbourhood composition for the stayers' sample. There is little overall change in the neighbourhood means of KS1 scores, or FSM, SEN, and male proportions. Given that during this period there were no evident national trends in these variables, this suggests neighbourhoods with stayers are not changing in ways that are significantly different from those of neighbourhoods without any stayers.

Figure 1 uses histograms to display the extent of variation in grade 6 to 9 neighbourhood turnover in the stayers' sample. The top-left plot shows that, although nearly $20 \%$ of the neighbourhood-by-cohort observations experience no mobility, there is a substantial amount of variation overall. The remaining plots show the distribution of the residuals from regressions of turnover rates on the various sets of fixed effects employed in the main regression analysis below. These plots show that there is considerable variation in neighbourhood-by-cohort turnover rates even

TABLE 1. Descriptive statistics of the main dataset.

Variable

Mean Standard deviation

Panel A: Students' characteristics, stayers only

KS2 percentiles, average English, Mathematics, and Science

KS3 percentiles, average English, Mathematics, and Science

$\mathrm{KS} 2$ to KS3 value added

Mean Standard

KS1 score, average English, and Mathematics

$\begin{array}{rc}50.037 & 25.249 \\ 51.143 & 25.837 \\ 1.106 & 13.590 \\ 15.108 & 3.617 \\ 0.158 & 0.364 \\ 0.213 & 0.410 \\ 0.508 & 0.499 \\ 1084.3 & 384.77\end{array}$

Student is free school meal (FSM) eligible

Student has special education needs (SEN)

Student is male

Secondary school size (in grade 7)

1084.3

384.77

Panel B: Mobility and other characteristics of neighbourhoods

Annual turnover of neighbours from grade 6 to 9

Annual exit rate of neighbours from grade 6 to 9

Annual entry rate of neighbours from grade 6 to 9

$\begin{array}{rr}0.145 & 0.128 \\ 0.064 & 0.068 \\ 0.081 & 0.093 \\ 0.204 & 0.194 \\ 15.020 & 2.438 \\ -0.031 & 1.446 \\ 0.166 & 0.251 \\ 0.005 & 0.145 \\ 0.221 & 0.252 \\ 0.002 & 0.165 \\ 0.509 & 0.292 \\ 0.002 & 0.165 \\ 5.343 & 2.565 \\ -0.013 & 1.467\end{array}$

Primary school neighbours' annual turnover from grade 3 to 6

KS1 score, average English and Maths_-grade 6

KS1 score, average English and Maths - change grade 6 to 9

Share free school meal (FSM) eligible students—grade 6

Share free school meal (FSM) eligible students—change grade 6 to 9

Share special education needs (SEN) students—grade 6

Share special education needs (SEN) students—change grade 6 to 9

Share male-grade 6 to 9

Share male-change grade 6 to 9

Number of students in neighbourhood, grade 6

Number of students in neighbourhood, change grade 6 to 9

Notes: Descriptive statistics refer to students who do not change OA of residence in any period between grade 6 and 9 in the nonselective part of the education system. Number of "stayers": approximately 1,210,000 (evenly distributed over four cohorts). Number of output areas: approximately 133,000. KS2 and KS3 refer to average test scores in English, Mathematics, and Science (percentalised) at Key Stage 2/grade 6 and Key Stage 3/grade 9 , respectively. KS1 refers to the average test score in reading, writing, and mathematics at the Key Stage 1 exams in grade 2 . 

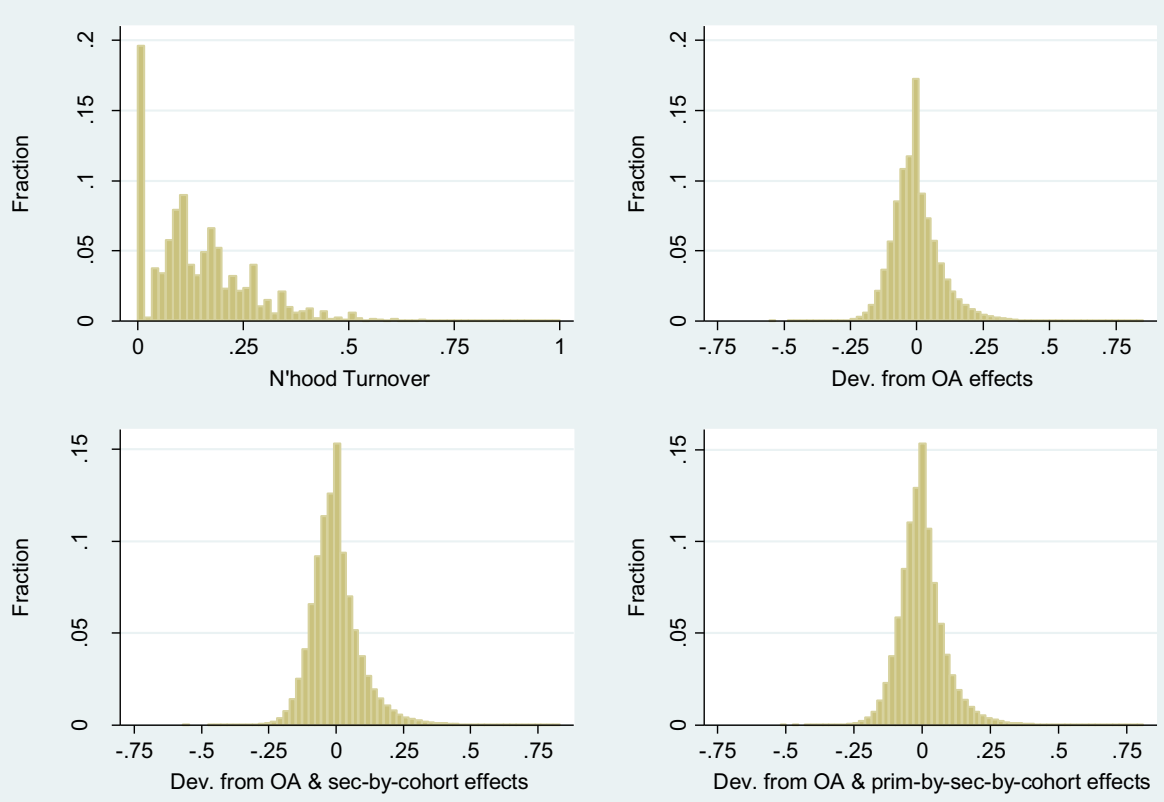

FIGURE 1. Variation in turnover in the neighbourhood. Descriptive statistics of neighbourhood mobility: mean 0.145 ; s.d. 0.128 . Descriptive statistics of deviations from neighbourhood (OA) effects: mean 0.000; s.d. 0.093. Descriptive statistics of deviations from OA and secondary schoolby-cohort effects: mean 0.000; s.d. 0.091. Descriptive statistics of deviations from OA and primaryby-secondary-by-cohort effects: mean 0.000 ; s.d. 0.084 .

when we control for either neighbourhood fixed effects (top right), or neighbourhood and secondary school-by-cohort fixed effects (bottom left), or neighbourhood and primary-by-secondary-by-cohort fixed effects (bottom right). The numbers in the notes to the figure show that the standard deviation of turnover moves from 0.128 to 0.098 when controlling for neighbourhood fixed effects. This shows that the variance in neighbourhood-by-cohort turnover within neighbourhoods is around $60 \%$ of the total variance. The standard deviation in turnover changes little as we further control for school-by-cohort effects.

We also find that our turnover measure is significantly correlated with the number of property transactions at the neighbourhood level—even conditional on neighbourhood fixed effects. This is important as it shows that our results are not just picking up the mobility of renters, who might have lower degrees of social connectedness in the neighbourhood compared to owners (DiPasquale and Glaeser 1999; Hilber 2010).

\subsection{Main Findings from the Regression Analysis}

Our main set of regression results on the effects of turnover on stayers' value added is presented in Table 2. The table reports regression coefficients and standard errors (s.e.), clustered at OA level to allow for spatial and temporal autocorrelation and 


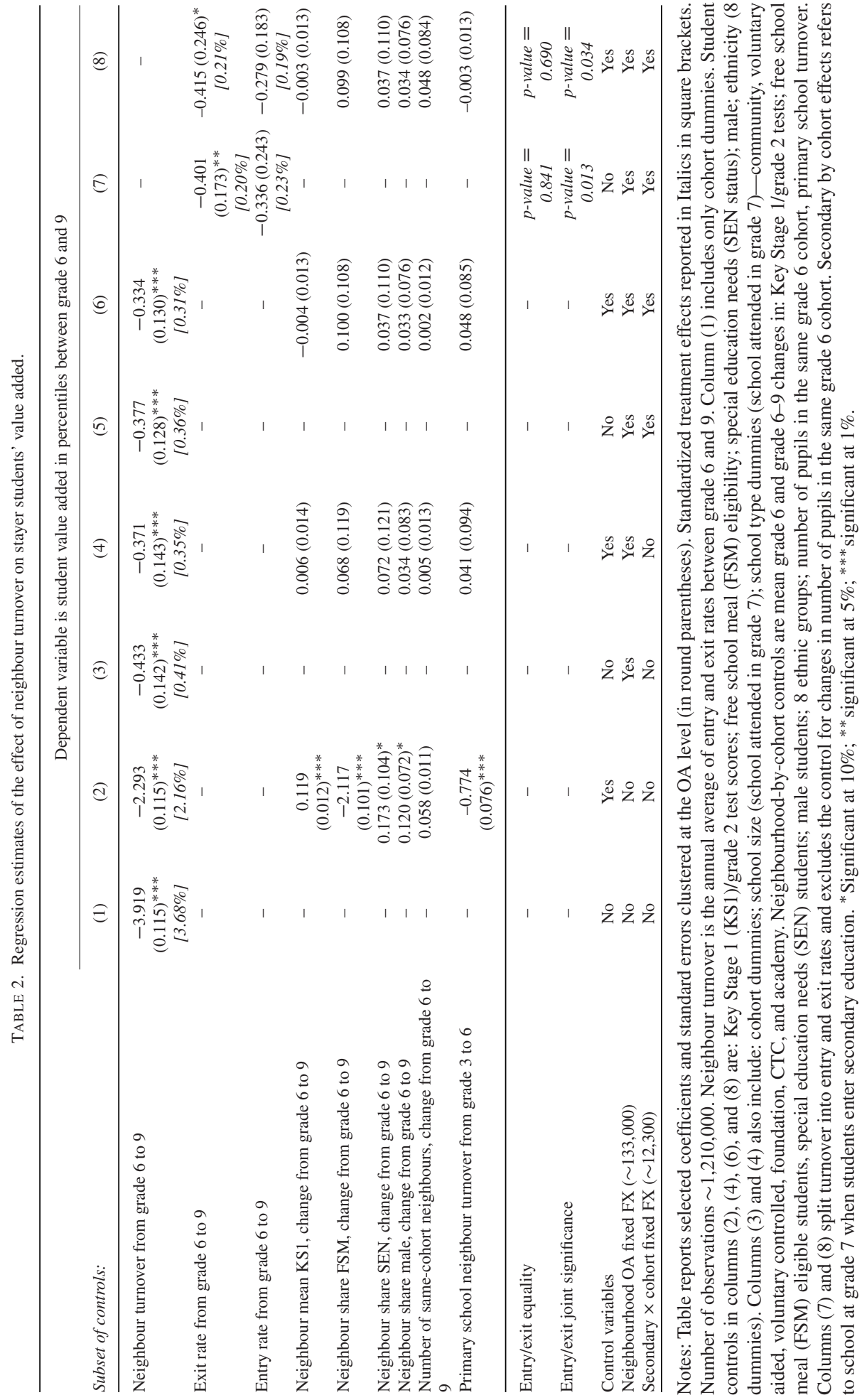


heteroscedasticity. Clustering at a higher level—for example, at the LEA level—does not affect the significance of our findings. A subset of the estimated coefficients on the most relevant neighbourhood-by-cohort control variables (described in Section 2) are reported to allow for a comparison of turnover and composition effects.

The coefficients on turnover present the effect of a 100 percentage point increase in the annual turnover rate on the percentile test score gain-that is, they correspond to a hypothetical change from no one in the neighbourhood moving in a year to everyone moving. In the discussion below we also report standardised turnover effects. These are obtained by multiplying the coefficients by 0.942 (that is by $100 \times$ the standard deviation of turnover divided by the standard deviation of KS2-KS3 value added from Table 1). These standardised turnover effects represent the percentage standard deviation change in value added associated with a one standard deviation change in mobility.

Column (1) shows the association between neighbours' turnover and pupil value added without any control variables other than cohort dummies. The coefficient of -3.9 implies that a standard deviation increase in annual turnover $(12.8 \%)$ is associated with a $3.7 \%$ of one standard deviation (\% s.d.) reduction in test scores. However, this estimate is likely to be biased by unobserved school and neighbourhood factors as discussed in Section 3, and is sensitive to the inclusion of our basic set of covariates, with a $40 \%$ reduction in the coefficient when moving from columns (1) to (2). There are also implausibly large, statistically significant associations between changes in the neighbourhood composition and stayers' test score gains. ${ }^{14}$ In short, these results serve as a (biased) baseline against which to judge the success of our identification strategy.

Column (3) introduces neighbourhood fixed effects, which are the key element in our research design. The coefficient on neighbour turnover falls dramatically to -0.433 (a standardised effect size of $0.40 \%$ s.d.). Importantly, column (4) shows that adding our extensive set of control variables now makes little difference to the estimated effect of turnover, changing it by only approximately $14 \%$. Furthermore, the coefficients on the neighbourhood composition variables are now very small and individually and jointly insignificant ( $p$-value on a joint-significance test $=0.974$ ) suggesting that changes in neighbourhood composition have zero effect on students' value added (consistent with Gibbons at al. 2013). For example, the association between value added and changes in the neighbourhood average KS1 test scores goes from being precisely estimated-at 0.119 in column (2) — to a miniscule 0.006 in column (4), which is clearly indistinguishable from zero at all conventional levels of significance. These findings reinforce our argument that controlling for small neighbourhood fixed effects is sufficient to control for unobservables that are correlated with turnover and that our estimates pin down the causal external effect of neighbourhood mobility. Moreover, they highlight the fact that our estimates isolate the impact of turnover-over and above any effect of changes in neighbours' characteristic driven by mobility.

14. These results are implausible given our previous evidence of insignificant effects of neighbours' characteristics on students' value-added (Gibbons et al. 2013). 
Columns (5) and (6) introduce secondary school-by-cohort fixed effects alongside neighbourhood fixed effects. These fixed effects control in a flexible way for any secondary school-level shocks that are correlated with neighbourhood turnover, in particular for common effects across neighbourhoods induced by student turnover at school that has been shown to matter in previous work (Gibbons and Tehaj 2011). As noted in Section 3, it is feasible to include these fixed effects because students living in the same neighbourhood attend on average two to three different secondary schools. Introducing school-by-cohort fixed effects makes little difference to the turnover coefficient, and the estimate is even more insensitive to the inclusion of the full set of neighbour and student control variables. The coefficient on turnover is now between -0.33 and -0.38 (corresponding to standardised effect size of $0.31-0.36 \%$ s.d.). Again, the coefficients on the neighbour-by-cohort control variables are small and statistically insignificant. In some subsequent robustness checks, we go one step further and control for primary-by-secondary-school-by-cohort fixed effects. We find that this makes almost no difference to the turnover coefficient (see Table 4). Therefore, we consider the empirical model presented in column (6) of Table 2 as our preferred specification, and use it for most of the results we discuss in the remainder of the paper.

An important point emerging from Table 2 is that there is no association between primary school children's turnover and the value added of secondary school children once we control for neighbourhood fixed effects (see the last row of coefficients). This finding sheds some light about the potential mechanisms at work: it is the turnover of same-grade children that seems to matter the most. We look more into this and related issues in subsequent empirical results (Table 7).

In the final two columns of Table 2, columns (7) and (8), we split the turnover measure into exit rates and entry rates, and estimate the effects of these in the same regression. Although the point estimate of the effect of exits is somewhat larger (at -0.42 vs. -0.28 for inwards mobility) and more precisely estimated, the two effects are jointly statistically significant and a test of equality cannot reject the null. This finding suggests the severing of friendship ties through neighbours leaving could be more disruptive than the entry of new neighbours, although evidently the arrival of new neighbours matters and there is no theoretical reason to think that entry of new potential friends or adversaries is not in itself disruptive. In fact, the social psychology and sociology literature summarised in Levine and Hogg (2010) points out that the arrival of new members in tightly knit groups can be as disruptive as the departure of existing members of the network. The statistical similarity in the coefficients also supports our arguments that we are estimating the causal effects of random changes in turnover, rather than the spurious impact of "flight" due to general neighbourhood decline or influx due to neighbourhood improvements-i.e., "gentrification"-which might directly affect the achievements of the stayers. Given the statistical similarity between the coefficients on entry and exit, we look mainly at the general effect of turnover in the empirical analysis that follows. However, we consider again the separate effects of neighbours' inflows and outflows in Table 8 where we study the impact of turnover on social networks. 
In terms of economic importance, the estimates and associated standardized effects of the impact of student neighbours' turnover seem small when scaled against the distribution of test score gains across the student population. However, the impacts of nearly all education interventions are small when scaled in this way, and our standardized effects are larger or comparable to the effects of other forms of social interaction-based spillover in the schools literature. Moreover, pupils spend up to eleven years in compulsory education so the cumulated effect of annual neighbour mobility over the course of their education could be substantial (almost four times the three-year effects we estimate here). We expand on the magnitudes of the effects in Section 6.

In the remainder of this section, we present more evidence to support the robustness of our causal interpretation of the results in Table 2, and study patterns of heterogeneity in the effect of turnover.

\subsection{Balancing and Robustness Checks}

In Table 3, we assess the extent to which neighbours' turnover is correlated with observed pupil, school, neighbourhood, and housing market characteristics. The aim is to understand whether high and low turnover areas are "balanced" in terms of observable characteristics, conditional on neighbourhood fixed effects, which are the key elements of our identification strategy. The table is divided into five panels, which report the coefficients and standard errors from separate regressions of various pupil (Panel A), school (Panel B), older neighbour pupils (Panel C), accessible schools (Panel D), and housing market (Panel E) attributes on turnover. Column (1) includes no control variables other than cohort dummies, whereas column (2) includes neighbourhood fixed effects and cohort dummies. The various characteristics are detailed in the table labels and notes.

Column (1) shows strongly significant and sizeable associations between neighbours' turnover and a host of individual, school, and neighbourhood features. The signs of these relations suggest that areas with higher levels of turnover are inhabited by more disadvantaged pupils who attend more disadvantaged schools. However, once we include neighbourhood fixed effects in column (2), all the coefficients shrink dramatically - to at most $1 / 10$ th and in most cases to less than 1/50th of their original magnitude-with little effect on the associated standard errors. As a result, all but three of the 21 coefficients are now statistically insignificant at the $10 \%$ level. Only two coefficients — secondary school size and students' own KS1 test scores—are marginally significant at just below and just above the 5\% threshold. Given that we have 21 tests, the probability of false positives is high: a Bonferroni correction would require a $p$ value of 0.0024 to ensure significance at the $5 \%$ level. Another way of looking at this is that the probability of at most two of these 21 tests being significant at the $5 \%$ level is $57 \%$ assuming the tests are independent (the probability will be even higher taking into account the fact that the dependent variables are correlated). Overall, Table 3 suggests that there is no association between cohort-to-cohort changes in turnover within the small neighbourhoods defined by OAs and the cohort-to-cohort changes in 
TABLE 3. Balancing properties of neighbour turnover.

Treatment is neighbourhood mobility—grade 6-9

$(1)$

Unconditional

$\begin{array}{lrr}-0.363(0.147)^{* *} & -0.020(0.191) & 2.593 \\ -1.631(0.031)^{* * *} & 0.069(0.035)^{*} & 15.12 \\ 0.200(0.004)^{* * *} & -0.004(0.003) & 0.158 \\ 0.094(0.003)^{* * *} & -0.004(0.004) & 0.213 \\ -0.003(0.004) & -0.002(0.005) & 0.508 \\ & & \\ -0.920(0.013)^{* * *} & -0.006(0.008) & 15.03 \\ -7.279(0.102)^{* * *} & 0.004(0.064) & 49.44 \\ -0.055(0.019)^{* * *} & 0.004(0.019) & 23.98 \\ -0.010(0.005)^{* *} & 0.007(0.003)^{* *} & 6.915 \\ & & \\ -18.01(0.273)^{* * *} & 0.090(0.283) & 45.67 \\ -18.74(0.273)^{* * *} & 0.298(0.281) & 49.35 \\ 0.190(0.003)^{* * *} & 0.004(0.003) & 0.146 \\ 0.169(0.003)^{* * *} & -0.006(0.004)^{*} & 0.137 \\ & & \\ 0.072(0.006)^{* * *} & -0.007(0.008) & 0.153 \\ 0.146(0.012)^{* * *} & -0.005(0.015) & 0.309 \\ -14.67(0.210)^{* * *} & -0.122(0.074) & 54.65 \\ 1.627(0.025)^{* * *} & 0.017(0.011) & 8.066 \\ -74.78(1.150)^{* * *} & 0.419(0.492) & 15.05 \\ -38.87(2.502)^{* * *} & 0.054(1.027) & 16.45 \\ -0.035(0.004)^{* * *} & -0.003(0.002) & 0.864 \\ 0.014(0.003)^{* * *} & 0.002(0.002) & 0.072\end{array}$

(3)

Neighbourhood fixed

Mean
Panel A: Pupil level characteristics

KS1 to KS2 value added

KS1 score, average English, and Maths

Student is FSM eligible

Student is SEN

Student is male

Panel B: Attended school characteristics

Grade 7 school average KS1 score

Grade 7 school average KS2 score

Grade 7 school s.d. KS2 score

Secondary school size (in grade 7; in log)

Panel C: Neighbourhood characteristics (older pupils)

KS3 test scores-pupils aged 14

GCSE test scores-pupils aged 16

FSM eligibility—pupils aged 14

FSM eligibility — pupils aged 16

Panel D: Accessible school characteristics

Number of schools opening within $5 \mathrm{~km}$

of pupil's residence

Number of schools closing within $5 \mathrm{~km}$

of pupil's residence

Percentage students achieving $5 \mathrm{~A}^{*}-\mathrm{C}$

GCSEs-accessible schools

Percentage days absent-accessible schools

Panel E: Housing market characteristics

House prices (hedonic) —all neighbourhoods

House prices (hedonic)—high homeownership areas

Share of sold properties that are freehold

Share of sold properties that are flat

Notes: Table reports coefficients and standard errors clustered at the OA level in parentheses from regressions of one of the dependent variables on neighbourhood turnover and year dummies. Regressions at the individual level for students staying in the same neighbourhood (OA) between grade 7 and 9. Number of observations: approximately 1,210,000. All specifications include year dummies. Column (1) does not include any additional controls. Column (2) includes neighbourhood (OA) fixed effects $(\sim 133,000$ groups). Column (3) reports the mean of the dependent variables. KS1, KS2, and KS3 refer to Key Stage 1/grade 2, Key Stage 2/grade 6, and Key Stage 3/grade 9 tests. GCSE refers to General Certificate of Secondary Education/grade 11 tests. $5 \mathrm{~A}^{*}-\mathrm{C}$ GCSE is the national GCSE target. Test scores averaged across English, Mathematics, and Science (or English and Mathematics only for KS1) and standardized (except for KS1 where they are left in the original scale measuring terms of progress). FSM identifies pupils eligible for free school meals. SEN identifies pupils with special education needs. Panel A presents results with student characteristics as the dependent variables. Panel B presents results for the characteristics of the school attended by students in grade 7 as described in labels. Panel $\mathrm{C}$ presents results for test score results and eligibility for free school meals of children aged 14 (KS3/grade 9) and age 16 (GCSE/grade 11) and living in the OA of residence of our sample of stayers when the latter are at the end of primary school (grade 6). Panel D presents results for the average characteristics of the set of schools accessible from the neighbourhood as described in the labels. Accessible schools include the set of secondary schools that stayers attend from a given OA. Panel E presents results for the housing market characteristics described in labels. House prices (in thousands of GB pounds) are regression adjusted for housing type (detached, semi-detached, terrace, flat), year and month of transaction; legal status (freehold or leasehold) and new/resale property. High home ownership neighbourhoods are OAs with more than 90\% (top 25th percentile) ownership rate. Share of freehold properties refers to share of properties in which owners own the land (i.e., noncondominium properties). Housing market information obtained from the Land Registry dataset that covers all property sold and purchased in England. * Significant at $10 \% ;{ }^{* *}$ significant at 5\%; *** significant at $1 \%$. 
the observables of neighbours, local schools, and the local housing market. It therefore seems highly unlikely that there is an association between changes in turnover and unobserved changes at neighbourhood level, which provides strong support for our identification strategy.

To further validate our results, we perform additional robustness checks in Table 4. Column (1) reports our baseline specification from column (6) of Table 2. The remaining columns in Table 4 differ in terms of the specification, measures of neighbourhood mobility used, and the sample of students retained for estimation as described in the table headings.

We start by addressing broad concerns with the empirical model we adopt. In column (2), we change our specification from one where percentile test score gains between KS2 and KS3 feature as the dependent variables, to the alternative commonly applied value added specification with KS3 percentiles as the dependent variable and KS2 percentiles as a control (i.e., a "lagged dependent variable" approach). This specification is more flexible in allowing for mean reversion in underlying achievement, but is also potentially biased by mean reversion due to transient components in the KS2 test scores. This approach yields an almost identical estimate of the effect of neighbourhood mobility at approximately -0.327 (s.e. 0.121 ), almost identical to the baseline at -0.334 (s.e. 0.130). ${ }^{15}$ In column (3), we control more aggressively for school unobserved shocks by replacing secondary school-by-cohort fixed effects with secondary-by-primary-by-cohort fixed effects ( 185,000 groups), alongside neighbourhood fixed effects. These estimates live off the cohort-to-cohort deviations from neighbourhood trends in value added and turnover within groups of students attending the same primary and moving on to the same secondary school. Even using this fine-grained level of variation we obtain a highly statistically significant estimate of -0.31 , which is very similar to the baseline at -0.33 .

The next two columns investigate how the neighbourhood definition we adopt affects our findings. To start, in column (4) we drop the $30 \%$ lowest population neighbourhoods to check that our results are not reliant on turnover generated from just a handful of moves in very small neighbourhoods. The estimate is slightly larger in magnitude at -0.42 , although less precisely estimated and statistically indistinguishable from our preferred estimates. Next, we address whether the spatial scale of our neighbourhood definition is appropriate by recomputing the turnover measures and the neighbourhood control variables at a larger lower layer super output areas (LSOA) level. LSOAs are census units containing on average six OAs. Column (5) reports the corresponding regression coefficients and standard errors (clustered at the LSOA level). The coefficient drops to -0.135 and is statistically insignificant. Evidently, mobility in the immediate OA is more relevant than mobility over a wider area and our OA-based definition of small neighbourhoods is to be preferred. This is to be expected if the impact of mobility is related to the disruption of friendship

15. To reduce biases due to transient noise components of lagged test scores, we also instrumented the lagged KS2 percentiles with teacher-based assessments of achievement based on longer-run teacher observation prior to the KS2 tests. This method gives very similar results (point estimate: 0.347; s.e. 0.126). 


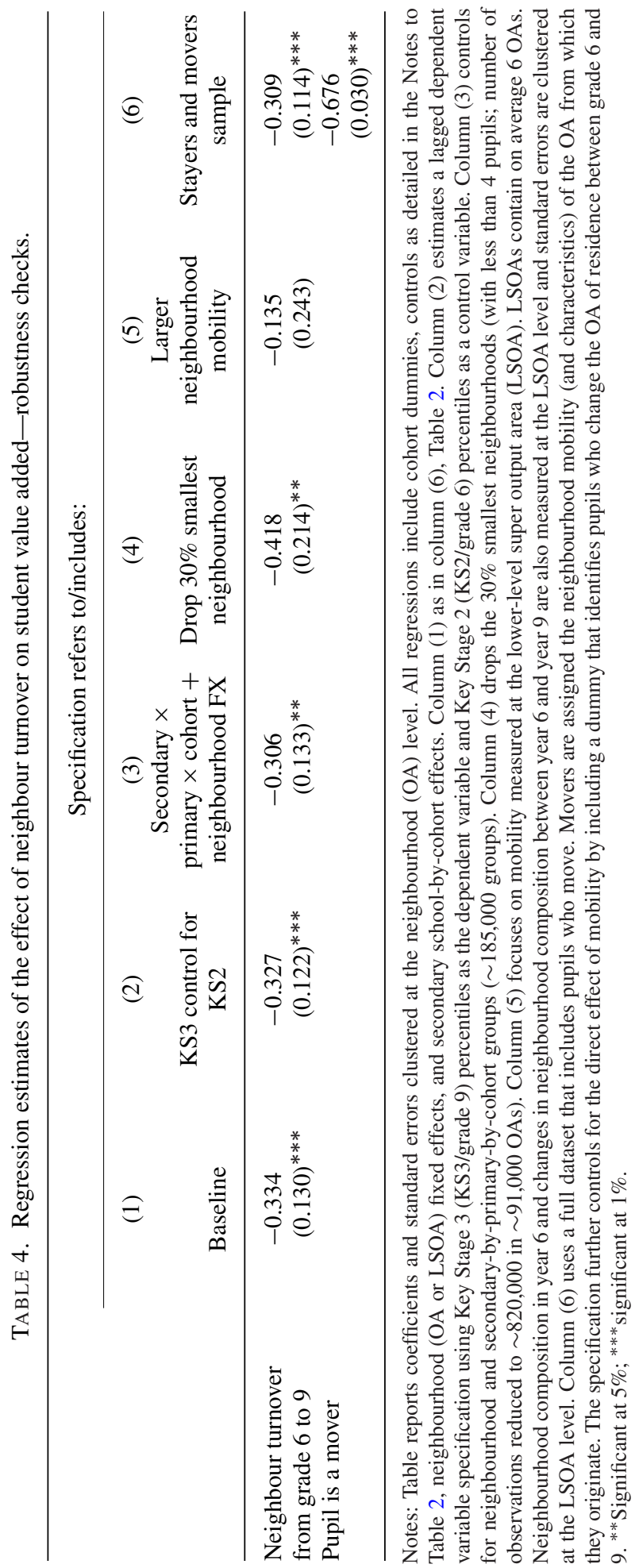


TABLE 5. Heterogeneity in the effect of neighbour turnover-by stayer pupil characteristics.

Dependent variable is value added in percentiles between grade 6 and 9

Neighbour turnover from grade 6 to 9 ; stayer student has/is:
(1)

(2) Low Key Stage 1 Test
(3)

(4)

\begin{tabular}{lcccc}
\hline Yes & -0.340 & -0.472 & -0.192 & -0.496 \\
& $(0.158)^{* *}$ & $(0.270)^{*}$ & $(0.214)$ & $(0.161)^{* * *}$ \\
No & -0.333 & -0.305 & -0.374 & -0.166 \\
& $(0.170)^{*}$ & $(0.137)^{* *}$ & $(0.142)^{* * *}$ & $(0.163)$ \\
Difference & 0.007 & 0.167 & 0.182 & 0.330 \\
& $(0.201)$ & $(0.280)$ & $(0.228)$ & $(0.194)$ \\
\hline
\end{tabular}

Notes: Table reports coefficients and standard errors (in parentheses) clustered at the neighbourhood (OA) level. Differences between the point estimates and associated standard errors are reported in Italics at the bottom of the table. All regressions include cohort dummies, controls as detailed in the Notes to Table 2, neighbourhood (OA) fixed effects and secondary school-by-cohort effects. Results obtained from regressions pooling all students and interacting individual characteristic specified in the heading with neighbourhood mobility. Number of observations $\sim 1,210,000$ in $\sim 133,000$ OAs. Low Key Stage 1 test refers to pupils with Key Stage 1/grade 2 test (averaged across English and Mathematics) below the sample median. * Significant at 10\%; ${ }^{* *}$ significant at 5\%; *** significant at $1 \%$.

ties and assuming students are more likely to form connections with their next door neighbours and others very close by. We return to this point in Section 5.1 where we provide evidence consistent with this intuition.

Lastly in column (6) we consider whether our results are biased by selectivity issues related to the fact that our estimation sample only contains pupils who do not move. To do so, we augment our sample with pupils who move and assign them to the turnover they would have experienced had they not changed residence (a type of "intention to treat" effect in the sense that it is the treatment movers would have received had they not moved). Note also that we control for the effect of pupils' own mobility, which we report as a control (without causal interpretation) in the second row. The estimate in column (6) shows that the association between value added and turnover is now -0.31 , with an associated standardised effect of $0.30 \%$ s.d. This is fully in line with the estimate obtained on our main sample.

\subsection{Heterogeneity by Individual and Neighbourhood Characteristics}

In this section, we investigate whether the effects of turnover differ for pupils with different individual characteristics (Table 5) or living in neighbourhoods with different characteristics (Table 6). In both tables, the results are obtained by re-estimating our preferred specification (displayed in column (6) of Table 2), but with additional interactions between dummy variables for the characteristics of interest (listed in the table headings) and the neighbourhood turnover rate. Note that in Table 6, where the underlying neighbourhood characteristics are continuous variables, the interactions are with dummy variables for the above-median and below-median values. 


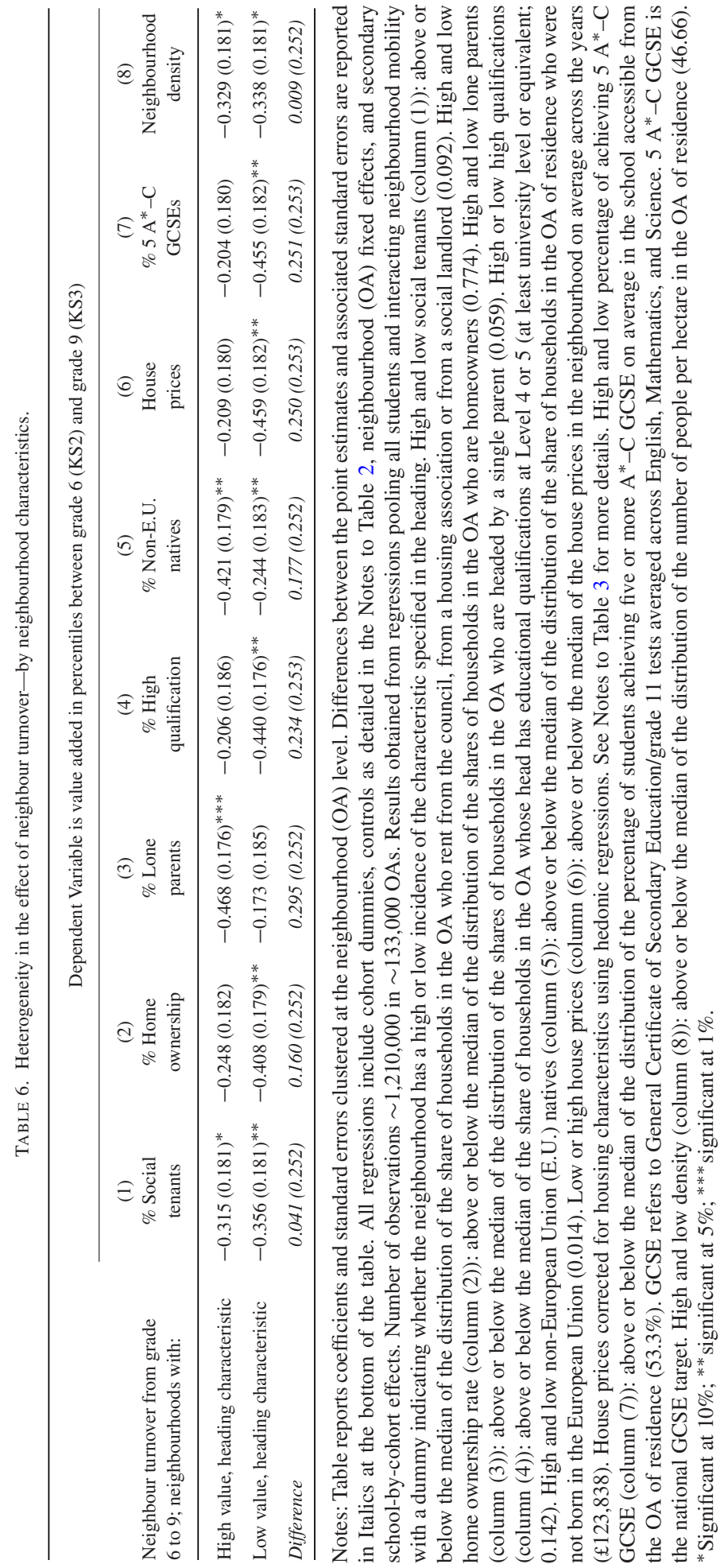


Starting with Table 5, the results suggest broadly similar effects across different types of student, although the point estimates are larger for poor pupils on free school meals, pupils without special educational needs and boys. None of these differences is statistically significant at the $5 \%$ level. The most notable difference is the one between boys and girls, with the effect on girls around half that on boys, and statistically insignificant (boys: -0.5 , s.e. 0.16 ; girls: -0.17 , s.e. 0.16 ). The difference between the coefficients for boys and girls is borderline statistically significant ( $p$-value $=0.089$ ). This is consistent with previous research showing that boys and girls respond differently to a number of educational interventions, peer interactions and external circumstances (Cross and Madson 1997; Eagly 1978; Anderson 2008; Lavy et al. 2012), and with evidence suggesting that boys are more negatively affected than girls by neighbourhood changes that might lead to a disruption of their social ties and networks (Kling et al. 2005, 2007).

Table 6 presents patterns of heterogeneity along more dimensions using characteristics derived from the UK population census (from 2001) and housing market data, as well as from within our pupil census dataset. Specifically, the first five columns look at differences according to the proportions of residents who are in social housing; home owners; lone parents; highly qualified; non-E.U. natives. The last four columns instead investigate heterogeneity according to the average price of local houses; the share of older students obtaining 5 A*-C GSCEs (at age 16/grade 11); neighbourhood population density; and student population change. ${ }^{16}$ Because of household sorting, these area characteristics are highly correlated with the attributes of students in our estimation sample and their families. So the breakdowns in the table are best interpreted as differences in the response to turnover for students from different family backgrounds, rather than differences in response by the average student according to the type of neighbourhood in which he/she lives.

The results in Table 6 paint a fairly consistent picture in which the effects of mobility are more pronounced in neighbourhoods where families face greater disadvantages - that is, low homeownership, ${ }^{17}$ high proportions of lone parents, fewer highly qualified adults, fewer non-E.U. natives, lower house prices, and lower qualifications of older students (columns (2)-(7)). However, none of these differences is statistically significant at the $5 \%$ level. Furthermore, we find virtually no difference in the point estimates of neighbours' turnover between high and low social housing neighbourhoods, and between high and low population density areas (columns (1) and (8), respectively). The findings relating to homeownership and house prices are interesting in the light of research that suggests that owner-occupation promotes

16. House prices come from the Land Registry dataset which covers all housing transactions in England, and are regression adjusted for housing type (detached, semi-detached, terrace, flat, bungalow), year and month of transaction, legal status (freehold or leasehold), and new/resale property. Details of the construction for the other variables are in the table notes.

17. This difference is not driven by the fact that high turnover is a feature of low homeownership neighbourhoods since both types of areas are characterised by similar levels of mobility (approximately $13 \%$ and $16 \%$ in high and low homeownership areas, respectively). 
investment in social capital, and social capital is in turn associated with higher house prices (Hilber 2010). Again, this suggests that social ties might be the force behind the disruptive impact of neighbourhood turnover that we document, with the effects weaker in places where people have more extensive and diverse local social networks, where lost connections might be more easily replaced, and where new ones more easily created. ${ }^{18}$

In a set of unreported results we study, but fail to find any evidence of nonlinearties in the effect of turnover and no evidence of differences in the effects of grade 6$7,7-8$, and 8-9 turnover rates. We also find that the negative effect of turnover is slightly greater in neighbourhoods with declining student populations than increasing ones-in line with the results on exit and entry rates in Table 2-although again these differences are not significant. Finally, we find bigger effects in neighbourhoods where coresident students attend fewer different secondary schools (i.e., below the median of three schools): -0.642 (s.e. 0.182 ) versus -0.164 (s.e. 0.160 ), with a $p$-value of 0.070 for the test of equality. This is consistent with the idea the turnover is disrupting networks for students who know each other through school. We come back to this issue in Table 7.

To summarise, we find evidence that the disruptive impact of turnover is more marked for students living in more disadvantaged neighbourhoods. Previous literature in sociology, psychology, and economics suggests that high level of turnover might affect pupils' outcomes by disrupting their social ties, friendship networks and local "connectedness". A possible explanation for the stronger effects in more disadvantaged neighbourhoods is that social networks are weaker in these neighbourhoods (Lupton 2001; Dietz and Haurin 2003). In the next section, we try to flesh out the evidence on whether this type of mechanism could rationalise the evidence provided in the previous sections.

\section{Exploring the Mechanism: Evidence of Social Network Effects}

\subsection{The Importance of the Similarity between Movers and Stayers}

If disruption to social networks lies behind the impacts of turnover on pupil value added, then we might expect stronger effects on stayers from movers who are either closer to them in terms of their personal characteristics, or closer geographically, or who attend the same school. Table 7 explores these issues, by extending the analysis of heterogeneity in the effects of turnover to look at differences according to the similarity between movers and stayers. We use our preferred specification of Table 2, column (6), but compute two measures of turnover: one based on movers who share a characteristic with the stayers, and one based on movers who differ from the stayers on this dimension.

18. We also investigated whether our results are more marked for larger urban areas (e.g., the ten biggest cities in England) or specific to London only, but found that this is not the case. 


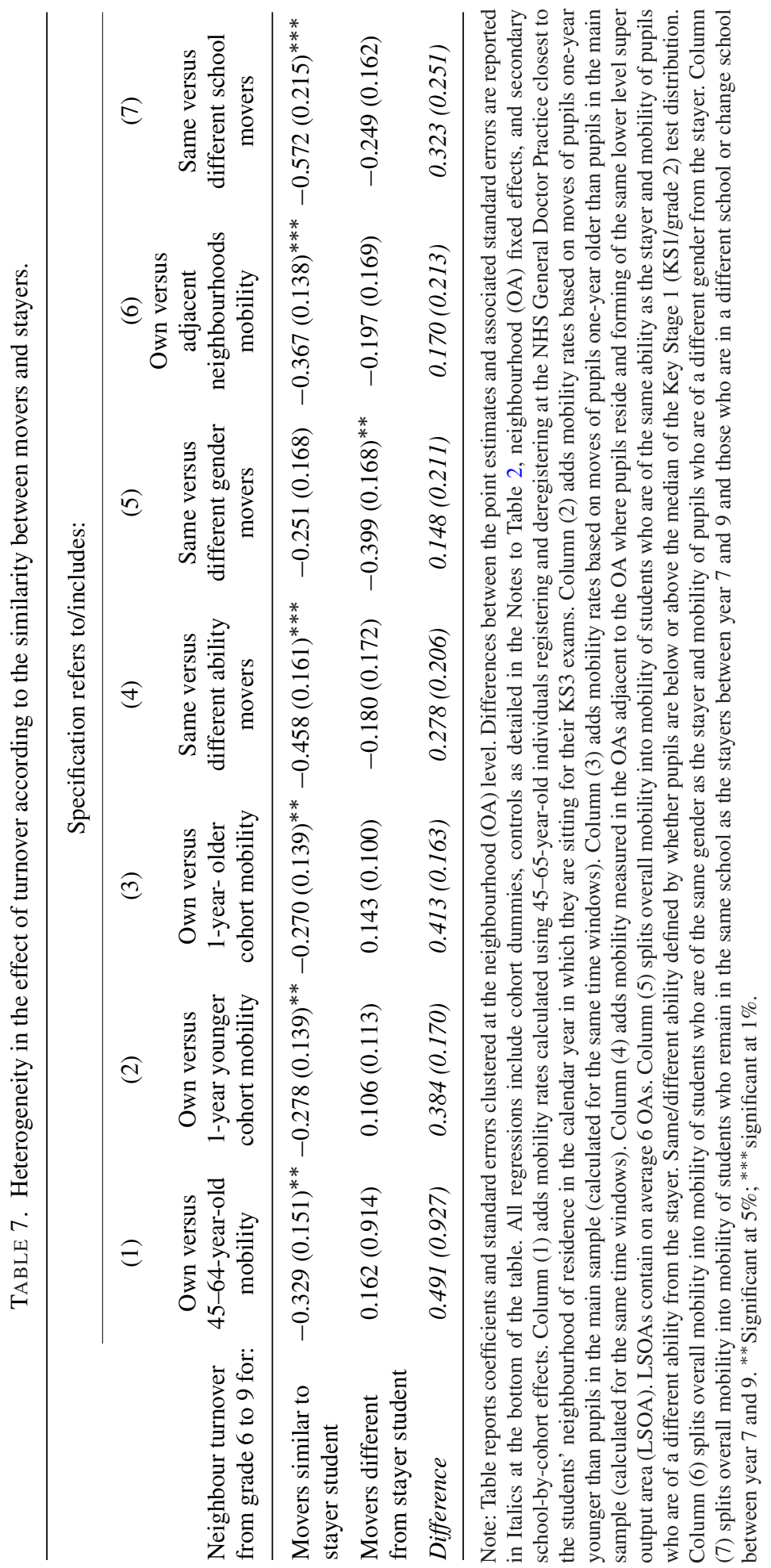


In columns (1)-(3) we focus on similarity in age. First, in column (1) we include our usual indicator of neighbourhood turnover alongside a measure of neighbourhood turnover of 45-64-year-old adults. Adult turnover is calculated using National Health Service (NHS) data on the number of individuals registering and deregistering from General Practitioners (GPs, local family doctors). ${ }^{19}$ When we include this variable in our regression, we still find that the turnover of same-grade pupils has a negative and significant effect whereas adult mobility has a nonsignificant positive effect. A similar pattern is seen in Columns (2) and (3) where include the usual measure of turnover based on movers who are in the same-grade as the stayers, alongside turnover computed using pupils who are one grade ahead or one grade behind the stayers (i.e., they are either one year younger or one year older). The effect of turnover of same-grade students remains largely unchanged. Conversely, we find no evidence that turnover of younger or older pupils matters. The differences between the same-grade and adjacent-grade coefficients are significant (with $p$-values of 0.024 and 0.012 , respectively in columns (2) and (3)). ${ }^{20}$ Taken together, the results in the first three columns of Table 7 clearly indicate that 11-14-year olds are unaffected by the turnover of adults who are unlikely to have children of their age and are only affected by students who are in exactly the same school grade as themselves.

Next in column (4) we look at similarity between movers and stayers in terms of prior ability by allowing the effects of turnover to differ according to whether samegrade movers and stayers have similar age-7 KS1 scores (above median/below median categories). We expect teenagers to be more connected with other youths of similar abilities due to assortative matching and therefore more likely to be affected by the turnover of students with similar skills. Carrell et al. (2013), for example, find that students form homogeneous subgroups in the US Air Force Academy (USAFA). The point estimates in column (4) are in line with this hypothesis: the effect of turnover is stronger when movers and stayers have similar KS1 scores, although the difference is not significant ( $p$-value $=0.176$ ). Table A.1 provides more detail on this relationship by splitting out the effects of both high KS1 and low KS1 movers on both high KS1 and low KS1 stayers. These results show that an inflow or outflow of high KS1 movers affects high KS1 stayers, whereas an inflow or outflow of low KS1 students affects low KS1 stayers (holding constant the composition of the neighbourhood).

19. This type of mobility is potentially relevant for our analysis since households usually register at a close-by local GP and change doctor when they move. We calculate the share of 45-64-year-old registrants and deregistrants for every GP practice in England for each year in which pupils in our data take their KS3. We then assign GP mobility numbers to each pupil's neighbourhood using the closest GP practice. Assigning pupils' neighbourhoods to the average mobility of the closest 3 or 5 GP practices does not change our findings. Similarly, using figures from the year before pupils sit for their KS3 exams produces similar results. Finally, using the shares of 15-64-year olds registering and deregistering from GP practices does not affect our findings.

20. Note that the correlation between turnover in one cohort and turnover among younger and older cohorts in the same neighbourhood is low and always below 0.20. This low correlation reinforces our argument that cohort-specific variation in neighbourhood mobility is "as good as random", and not driven by common neighbourhood shocks which affect all cohorts simultaneously and might have direct effects on student achievement. 
Although the differences in the point estimates across the various subgroups are not precisely estimated, the patterns are suggestive and lend further support to the assortative matching hypothesis.

When we look at the similarity between movers and stayers by gender (column (5)), the results are at first quite surprising. The coefficient on the turnover of the opposite gender is the larger and more statistically significant of the two estimates although again the difference between the two coefficients is not statistically significant ( $p$ value $=0.483$ ). Digging deeper, Table A.1 shows that the difference in the point estimates is driven by turnover of girls affecting boys. Of course, we can imagine credible reasons why young teenage boys might find the arrival and departure of samegrade girl neighbours disruptive to their education. It should however be noted that the effect of girls' turnover on boys is not statistically different from the effect of males' turnover on boys (and the two estimates are jointly significant). On the other hand, girls seem to be much less affected by turnover irrespective of the gender of the movers. This is consistent with the evidence we found in column (4) of Table 5.

The last two columns of the table look at questions related to proximity in physical space and institutions by focussing on whether movers and stayers are close residential neighbours and whether they go to secondary school together. Column (6) adds to the regression the turnover in the neighbourhood OAs adjacent to the OA where a stayer pupil resides, alongside the usual OA-based turnover variable. ${ }^{21}$ These results show that it is the mobility of the stayers' immediate neighbours that matters. This is in line with our expectation that bonds between close neighbours will be stronger, and the consequences of losing these connections more acute. Column (7) further investigates whether movers have a different impact on stayers depending on whether they go to the same secondary school. To simplify the analysis, we focus on the sample of neighbourhood stayers who also do not change their school (this restriction has virtually no effect on our main turnover estimate). We find that the estimated impact of turnover is bigger if movers attend the same school as the stayers, although the difference is not statistically different $(p$-value $=0.193$ ). Note that this finding cannot be driven by correlations between turnover and school-level unobservables because we continue to include secondary-by-cohort fixed effects in our specifications. The strength of the result for same-school movers and stayers is unsurprising because casual observation suggests that most young teenagers have friendship groups drawn from their current school. Even so, it is perfectly plausible that there is an effect on stayers from the turnover of same-grade neighbours who go to different secondary schools. This could be because movers and stayers know each other from primary school, because they know each other through the more extended set of same-grade

21. More specifically, we consider the mobility in OAs that are in the same LSOA as the stayer's OA of residence but excluding his/her own OA. Note that this is different from the exercise reported in column (5) of Table 4, where we conduct all the analysis of turnover at LSOA level (including the way in which we aggregate the controls for neighbourhood composition and its changes over time). The findings are however consistent. 
friends across the local schools network, or simply because neighbours of a similar age are more likely to have shared interests.

All in all, the evidence in Table 7 suggests that it is turnover of mover students who are similar to stayers - on dimensions of age, ability, proximity, and school attendedthat plays a strong role in reducing stayers' test score value added. This is consistent with the idea that these effects might be related to the closeness of actual and potential ties that are broken and formed as students leave and enter the neighbourhood, with high turnover making it hard to make friends and easy to lose them. In the next section, we provide further evidence consistent with this friendship-related mechanism.

\subsection{Students' Behaviour Using the LSYPE}

To gain more insights on the relationship between turnover and social ties, we turn to information collected through the LSYPE on pupils' friendship networks and leisure activities. The survey asked students aged 14 questions about their experiences at school, at home, and in their neighbourhood, and contains a number of questions related to pupils' friends and their use of free time. We use this information to construct the following five binary indicators (yes $=1 ; 0=$ no) of local social connections: (1) friends regularly visit the pupil's home; (2) the pupil visit friends' home when free; (3) the pupil has been excluded from a group of friends; (4) the pupil joins a youth club during his/her free time; and (5) the pupil hangs around at home during free time. More details about the original wording of the LSYPE questions and possible answers are provided in the notes to Table 8. We also follow Kling et al. (2007) and combine these variables into a composite "social connectedness" indicator by summing answers at (1), (2), and (4), and subtracting (3) and (5). More positive values of this indicator correspond to more socially connected pupils.

The descriptive statistics for the main variables constructed for the LSYPE sample are presented in Table A.2. These reveal that despite including only approximately 10,000 pupils who do not change residence between year 7 and 9, the sample is similar to our main data set and broadly representative of the national student population. We find that about $23 \%$ of the pupils have friends visiting their home regularly every week; $21 \%$ join youth clubs during their free time; and about $19 \%$ visit their friends' homes regularly. Conversely, $27 \%$ hang around the house when free, and $15 \%$ have been excluded from a group of friends or from joining activities in the past 12 months.

In Table 8 we present results from regressions that relate pupils' proxies for local social connections to the level of turnover in their place of residence. Note that these come from specifications where we cannot control for neighbourhood effects since we only have data for one cohort. However, we control for secondary school effects (columns (1)-(6)) and secondary-by-primary school effects (column (7)) to partial out any confounding shock that is common to pupils attending the same school-including school turnover. Moreover, on top of the individual- and neighbourhood-level variables included in the analysis so far, we exploit the richness of the information collected by the LSYPE to further control for these aspects of pupils' background (in column (7)): number of older siblings; number of younger siblings; whether the household is headed 


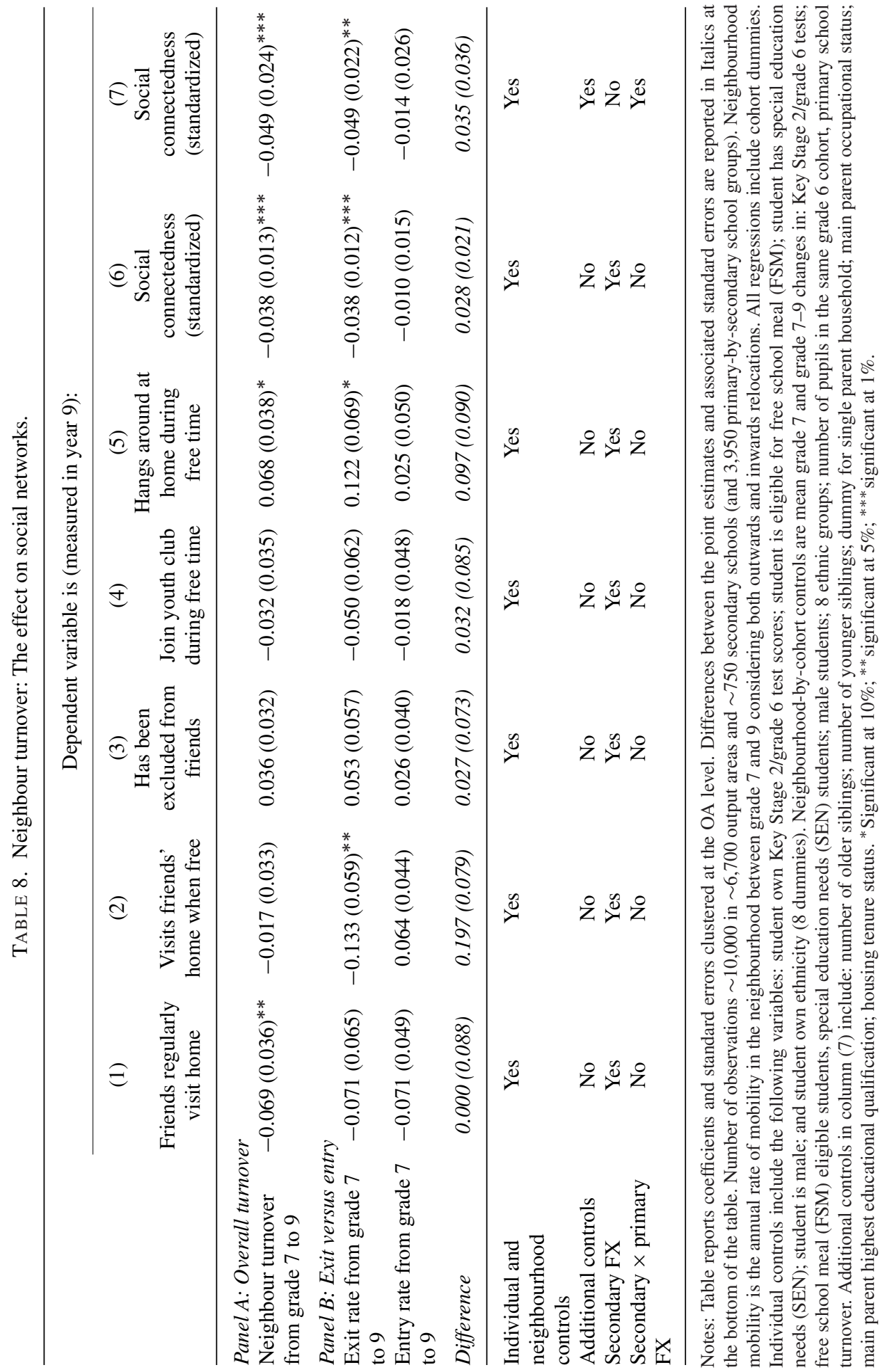


by a single parent; parental occupational status and highest educational qualification; housing tenure status. Panel A reports effects of overall turnover, whereas Panel B splits the overall mobility measure into outwards versus inwards mobility (similar to the last columns of Table 2).

Starting from Panel A, our findings clearly suggest that pupils who live in neighbourhoods with higher levels of turnover are less socially connected. A one standard deviation change in neighbourhood mobility reduces by 4.5 percentage points the probability that a pupil has friends regularly visiting his/her home, whereas it increases by $3.8 \%$ the chances that the pupil spends his/her free time hanging around the house-presumably alone. Although the other coefficients on the binary indicators are not statistically significant, they still present sizeable effects. For example, pupils in neighbourhoods with turnover one standard deviation above the mean are $2.3 \%$ less likely to join youth clubs during their leisure time and $3.7 \%$ more likely to have been excluded from groups of friends or from joining their activities than otherwise similar pupils. When considering our composite social connection indicator, we find sizeable and highly significant results. A one standard deviation increase in neighbourhood turnover decreases social connectedness by $3.8 \%$ of a standard deviation when only controlling for secondary school effects (column (6)), and by $4.9 \%$ when partialling out primary-by-secondary school shocks (column (7)).

Due to small sample sizes, we cannot fully replicate the analysis presented in Section 4.4 where we stratify our results by various pupil and neighbourhood subgroups. However, in some unreported extensions to our analysis, we find evidence that the negative effect of turnover on social connectedness is stronger in areas with a lower percentage of homeowner; a lower incidence of highly educated parents; a higher percentage of lone parents; and a higher share of non-E.U. natives. These patterns mirror the results presented in Table 6 and support our intuition that the effects of turnover are more negative in more disadvantaged areas because social networks are weaker in these types of neighbourhoods.

Panel B breaks up the turnover measure into inwards and outwards mobility. Overall, we find outwards mobility to be more detrimental, although the effect of inwards mobility always has the same sign and the point estimates are not statistically different. The only exception is column (2), where the difference between the effects of inwards versus outwards mobility is statistically significant at the $5 \%$ level. The evidence from our most saturated specification (in column (7)) shows that, despite being larger, the impact of outwards mobility on social connectedness is not statistically different from the effect of inwards mobility. This is consistent with the social psychology literature that suggests that it takes time and effort to befriend and get used to new members of one's social group, and that inflows of new individuals can be as disruptive as outflows of existing members of a friendship network (see Levine and Choi 2004; Levine and Hogg 2010).

These results are to be treated with some caution and are meant to be mainly supportive of our conjecture that broken social ties explain the negative impact of turnover on pupil attainment. This is because the LSYPE data-which sample only one cohort—do not allow us to partial out the confounding effects of neighbourhood 
unobservables by exploiting cohort-on-cohort variation. In our defence, we do control for the initial composition of the neighbourhood and its changes over time in terms of ethnicity, early achievements, gender, free-school meal eligibility, and special educational needs of children. Similarly, unlike our value added regressions, the results in Table 8 do not exploit changes in the outcome variables over timerather a single snapshot assessment taken at age 14. This means that family unobservables that lead to sorting of pupils with different propensities to be socially connected into neighbourhood with high/low levels of turnover might contaminate our findings. ${ }^{22}$ Nevertheless, our regressions control for a vast array family background characteristics - ranging from family size and composition to parental employment and education. Furthermore, we experiment with including in our specification some self-reported variables that capture whether children and their parents have good relationships. This does not affect our findings, though we prefer specifications that do not include these potentially endogenous controls.

In conclusion, we believe that-despite its small sample size-the evidence based on the LSYPE outcomes is informative and supports our interpretation that neighbourhood turnover negatively affects pupils' value added by disrupting their local ties, friendship networks, and social capital.

\section{Concluding Remarks}

In this paper, we have presented evidence that residential turnover of teenagers between ages 11 and 14 reduces the test score value added of same-grade, neighbouring students who do not move home. The effects are statistically significant, albeit quite small in magnitude. These findings are a new contribution to the empirical literature on the effects of neighbours on academic achievements. The existing research in economics has studied how neighbourhood composition affects pupils' learning through role model and peer effects, and found little evidence of a causal link. Our study shifts the focus to the spillover impact of neighbourhood turnover, and finds that it matters.

A potential mechanism behind this effect is that high turnover in the neighbourhood leads to disruption in the social ties and friendship networks between neighbours, because it takes time to adapt to new arrivals and get to know them, and because friendships are lost through people leaving. In an influential study, Granovetter (1973) argues that the degree of overlap of friendship networks - and thereby the overall strength of friendships within a group — varies directly with the strength of its bilateral relationships. As a result, if existing bilateral ties are weakened because existing members of the network move away or new individuals join in, the overall degree of social connectedness suffers. A subsequent literature in sociology and psychology has further argued that "turbulence" amongst a young person's social circles can have

22. Reassuringly, when we estimate the impact of neighbourhood turnover on pupil value-added for the LSYPE sample and using the specification presented in column (7) of Table 8, we find results consistent with our main findings - although less precisely estimated. 
detrimental effects on learning, and presented consistent evidence from small-scale and qualitative studies (e.g., Wentzel 1993; Roseth et al. 2008). Similarly, psychological small-scale experimental work on turnover and group outcomes finds negative effects (e.g., Argote et al. 2006). These intuitions have been backed by more recent studies in the economics fields that pin down the negative causal effect stemming from disruption in friendship networks when pupils have to change schools (Lavy and Sand 2012; Ly and Riegert 2014). Our findings are consistent with these arguments. We presented evidence that the effects are stronger in more disadvantaged neighbourhoods, where there may be lower levels of more general social capital and fewer family resources to compensate (Lupton 2001; Dietz and Haurin 2003). We showed that the effects are stronger when movers and stayers are in the same school grade, have similar abilities, live close together, and attend the same schools and hence more likely to form bonds. We also showed that students living in high turnover neighbourhoods are less socially connected. Although we speculate that the disruption to education comes about through the formation and severing of social ties between teenagers, there are of course complementary explanations. For example, turnover of teenagers implies turnover of their parents, who may in turn be the ones responsible for fostering local networks and social capital, and thus raising pupils' attainments. Either way, our evidence is generally important for our understanding of human capital formation as it clearly points to a previously neglected trade-off: although residential mobility might be good from an individual's perspective as well as for labour markets, this entails negative spillovers on immobile individuals that experience high rates of turnover-irrespective of exact mediating factors. Furthermore, our findings show that disadvantaged pupils are more negatively affected by higher rates of turnover — suggesting that neighbourhood "turbulence" might be a so-far neglected factor contributing to widening inequality in educational outcomes.

How big and policy relevant are these effects? Like many other estimated impacts in the education literature, our standardized impacts are small when compared to the distribution of test scores across students: our estimates imply a $0.35 \%-0.4 \%$ standard deviation change in pupil value added for a one standard deviation change in turnover. These effects are, however, similar to other estimates of social interaction-based spillovers on student achievement. Gibbons and Telhaj (2011), for example, find similar size effects from turnover in primary schools. But their school-based effects combine the disruptive effect of the change in a young person's social network with the adverse effect of pupil turnover on teachers' ability to focus their instruction time. The effects we estimate here operate in a different environment - the residential neighbourhoodand are net of any disruptive effects occurring at school (since we control for these through our school-by-cohort fixed effects). Therefore, our study is more finely tuned to capture the adverse effects of the disruption in social ties - a spillover arising purely from social interactions amongst teenagers. Studies of other types of neighbours' social interaction generally find no impact on test scores. For example, our previous study on the impact of the characteristics of same-grade neighbour peers (Gibbons et al. 2013) finds precisely estimated zero effects in the same school and neighbourhood context as the current work. Estimates of the effects of peer characteristics in England's 
schools are slightly larger-but not substantially so. For example, Lavy et al. (2012) and Gibbons and Telhaj (2016) find school-based peer group effect sizes of around a $1 \%-2 \%$ of one standard deviation (using data similar to ours and coming from the same institutional context).

Another comparison point is the impact of school resources. The results in this literature are wide ranging, with many older studies finding zero impact from additional spending, whereas recent work is more positive (Hanushek 2003; Gibbons and McNally 2013). Work on schools in England provides the most appropriate benchmark for our case, with a $£ 1000(20 \%-30 \%)$ increase in per-pupil spending generating a $2 \%-24 \%$ of one standard deviation increase in achievement (Holmlund et al. 2010; Gibbons et al. 2012; Nicoletti and Rabe 2014). Based on the estimates for secondary schools in Nicoletti and Rabe (2014), an additional $£ 90$ per pupil per year would be needed to compensate students from the highest turnover neighbourhoods (top 5\%) and bring their achievements in line with those in the lowest turnover neighbourhoods (in the bottom 5\%, at three standard deviation lower levels of mobility). The cost of neutralizing the negative external effect of neighbourhood turnover for every pupil would be around $£ 48$ million per year in total. ${ }^{23}$ Evidently, the costs of neighbours' turnover are not trivial in monetary terms-but could be quite easily compensated by small increases in the educational budget. Furthermore, our estimated effects are only around $3 \%$ of those associated with general measures of teacher effectiveness (Hanushek and Rivkin 2012). The negative impacts of turnover could therefore be similarly offset by policies that help recruit more effective teachers and/or incentivise their performance (e.g., Lavy 2009). For example, Imberman and Lovenheim (2015) show that group-based monetary incentives provided to teachers in the Houston Independent School District increased attainments in English and Mathematics by $3 \%$ and $10 \%$ of a standard deviation, respectively. Once again, this suggests that the effect that we identify in this paper is nontrivial—but could be more than compensated by performance-related teacher pay schemes.

Do our results call for policies that reduce individuals' mobility to avoid the external cost it imposes on pupils' learning? We do not believe so. Given the likely benefits of mobility in terms of the efficient allocation of human capital across space and adjustments to geographical changes in the economic landscape (Sjaasted 1962; Jovanovic 1979; Greenwood 1997), it is likely that the costs of policies that restrict individuals' mobility outweigh any benefit from reducing negative spillover effects of mobility. As outlined above, policies that address education inequalities caused by neighbourhood turnover by using targeted school resources hold more promise.

23. Using the descriptive statistics and coefficients in Table 1 and Table 2, the effect of a 3 s.d. change in turnover on Key Stage 3 levels is $3 \times 0.35 \times 0.128 / 25.8=0.0052$ standard deviations. If a $£ 1000$ increase in school resources raises Key Stage 3 attainment by 0.06 standard deviations (Nicoletti and Rabe 2014), then $£ 90$ per pupil per year would have to be spent to compensate the average pupil for this change in turnover. To obtain an estimate for the required expenditure for a whole grade, we multiply this figure by the number of students per cohort—approximately 550,000— giving $£ 48$ million per year. 


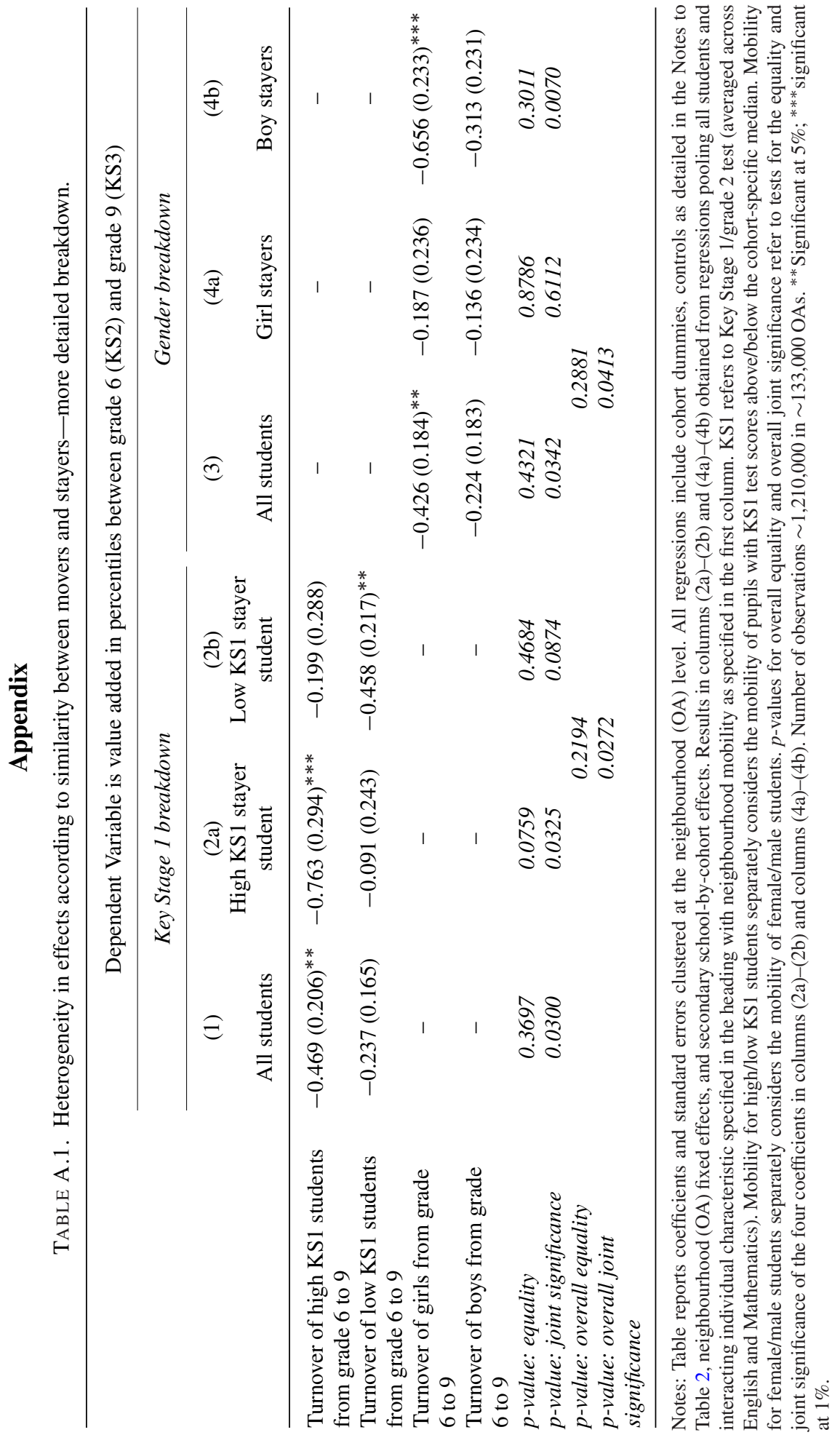


TABLE A.2. Selected descriptive statistics for the LSYPE dataset.

\begin{tabular}{|c|c|c|}
\hline Variable & Mean & $\begin{array}{l}\text { Standard } \\
\text { deviation }\end{array}$ \\
\hline \multicolumn{3}{|l|}{ Panel A: Students' characteristics, stayers only } \\
\hline Friends regularly visit home (yes $=1 ; 0=$ no) & 0.236 & 0.425 \\
\hline Visits friends' home when free (yes $=1 ; 0=$ no) & 0.186 & 0.389 \\
\hline Has been excluded from a group of friends (yes $=1 ; 0=$ no) & 0.150 & 0.357 \\
\hline Join youth club during free time (yes $=1 ; 0=$ no) & 0.214 & 0.410 \\
\hline Hangs around/messes at home during free time (yes $=1 ; 0=$ no) & 0.272 & 0.445 \\
\hline Composite 'social connectedness' indicator & 0.215 & 0.916 \\
\hline KS2 percentiles, average English, Maths, and Science & 50.07 & 25.22 \\
\hline Student is free school meal (FSM) eligible & 0.176 & 0.381 \\
\hline Student has special education needs (SEN) & 0.161 & 0.368 \\
\hline Student is male & 0.499 & 0.500 \\
\hline \multicolumn{3}{|l|}{ Panel B: Mobility and other characteristics of neighbourhoods } \\
\hline Annual rate of neighbour turnover from grade 7 to 9 & 0.128 & 0.154 \\
\hline Annual rate of primary school neighbour turnover from grade 4 to 6 & 0.215 & 0.213 \\
\hline KS2 score, average English, Maths, and Science—grade 7 & 49.27 & 17.45 \\
\hline KS2 score, average English, Maths, and Science-change grade 7-9 & -0.073 & 8.249 \\
\hline Share free school meal (FSM) eligible students—grade 7 & 0.181 & 0.275 \\
\hline Share free school meal (FSM) eligible students—change grade 7 to 9 & 0.003 & 0.124 \\
\hline Share special education needs (SEN) students-grade 7 & 0.171 & 0.243 \\
\hline Share special education needs (SEN) students—change grade 7 to 9 & -0.002 & 0.127 \\
\hline Share male—grade 7 & 0.499 & 0.309 \\
\hline Share male-change grade 7 to 9 & -0.002 & 0.169 \\
\hline Number of students in neighbourhood, grade 7 & 4.678 & 2.493 \\
\hline Number of students in neighbourhood, change grade 7 to 9 & -0.029 & 1.067 \\
\hline
\end{tabular}

Notes: Descriptive statistics refers to LSYPE students (one cohort aged 14 in 2004) who do not change OA of residence in any period between grade 7 and 9 . Number of stayers: approximately 10,000. Number of output areas: approximately 6,700. Number of secondary schools: approximately 750. KS2 refers to the average score in English, Maths, and Science at the Key Stage 2/grade 6 test (age 11). LSYPE outcome variables constructed from interviews carried out in year 9 (pupil aged 14) as follows. (1) Friends regularly visit home (yes $=1 ; 0=$ no) derived from the following question: "Thinking back over the last 7 days, have you had friends round to your house? Is it: "None" (coded 0); "Once or twice" (coded 0); "3-5 times" (coded 1); "6 or more time" (coded 1). (2) Visit friends' home when free (yes $=1 ; 0=$ no) derived from the following question: "When you have free time, do you mainly (multiple choices): go round to a friend's house (or friends come round to mine)" (coded 1; all valid alternatives coded 0). (3) Has been excluded from a group of friends derived from the following question: "In the last 12 months, have you ever been excluded from a group of friends of from joining in activities (yes $=1$; no $=0$ )". (4) Join youth club during free time derived from the following question: "Here is a list of some more things people do when they are not at school. Can you please tell me which, if any, you have been to or done in the last four weeks (multiple choices)? Gone to a youth club or something like it" (coded 1; all valid alternatives coded 0). (5) Hangs around/messes at home during free time derived from the following question: "Here is a list of some more things people do when they are not at school. Can you please tell me which, if any, you have been to or done in the last four weeks (multiple choices)? Just hung around/messed about at home" (coded 1; all valid alternatives coded 0). Composite "social connectedness" indicator is obtained as (1) + (2) + (4) - (3) - (5). More positive values correspond to more socially connected pupils. 


\section{References}

Aaaronson, Daniel (2000). "A Note on the Benefits of Homeownership." Journal of Urban Economics, 47, 356-369.

Anderson, Michael L. (2008). "Multiple Inference and Gender Differences in the Effects of Early Intervention: A Reevaluation of the Abecedarian, Perry Preschool, and Early Training Projects." Journal of the American Statistical Association, 103, 1481-1495.

Argote, Linda, Chester A. Insko, Nancy Yovetich, and Anna Romero (2006). "Group Learning Curves: The Effects of Turnover and Task Complexity on Group Performance." Journal of Applied Social Psychology, 25, 512-529.

Calvó-Armengol, Antoni, Patacchini Eleonora, and Zenou Yves (2009). "Peer Effects and Social Network in Education." Review of Economic Studies, 76, 1239-1267.

Carrell, Scott E., Bruce I. Sacerdote, and James E. West (2013). "From Natural Variation to Optimal Policy? The Importance of Endogenous Peer Group Formation." Econometrica, 81, 855-882.

Chetty, Raj, Nathaniel Hendren, and Lawrence F. Katz (2015)."The Effects of Exposure to Better Neighborhoods on Children: New Evidence from the Moving to Opportunity Experiment." American Economic Review, 106(4), 855-902.

Coleman, James (1988). "Social Capital in the Creation of Human Capital." American Journal of Sociology, 94, S95-S120.

Cross, Susan E. and Laura Madson (1997). "Models of the Self: Self-Construals and Gender." Psychological Bulletin, 12, 5-37.

Dietz, Robert E. and Donald R. Haurin (2003). "The Social and Private Micro-Level Consequences of Homeownership.” Journal of Urban Economics, 54, 401-450.

DiPasquale, Denise and Edward L. Glaeser (1999). "Incentives and Social Capital: Are Homeowners Better Citizens? Journal of Urban Economics, 45, 354-384.

Durlauf, Steven N. (1996). “A Theory of Persistent Income Inequality.” Journal of Economic Growth, $1,75-93$.

Eagly, Alice H. (1978). "Sex Differences in Influenceability.” Psychological Bulletin, 85, 86-116.

Gentry, William M. and R. Glenn Hubbard (2002). "The Effects of Progressive Income Taxation on Job Turnover." NBER Working Paper 9226.

Gibbons, Stephen and Sandra McNally (2013). "The Effects of Resources across School Phases: A Summary of Recent Evidence." Report for OfSted, London.

Gibbons, Stephen and Shqiponja Telhaj (2011). "Pupil Mobility and School Disruption.” Journal of Public Economics, 95, 1156-1167.

Gibbons, Stephen, Sandra McNally, and Martina Viarengo (2012). "Does Additional Spending Help Urban Schools? An Evaluation Using Boundary Discontinuities.” IZA Discussion Papers 6281.

Gibbons, Stephen, Olmo Silva, and Felix Weinhardt (2013). "Everybody Needs Good Neighbours? Evidence from Students' Outcomes in England.” The Economic Journal, 123, 831-874.

Gibbons, Stephen and Shqiponja Telhaj (2016). "Peer Effects: Evidence from Secondary School Transition in England." Oxford Bulletin of Economics and Statistics, 78, 548-575.

Granovetter, Mark S. (1973). "The Strength of Weak Ties." American Journal of Sociology, 78, $1360-1380$.

Greenwood, Michael J. (1997). "Internal Migration in Developed Countries." In Handbook of Population and Family Economics, edited by M. , Rosenzweig, and O. Stark. North-Holland, Amsterdam, pp. 647-720.

Hagan, John, Ross MacMillan, and Blair Wheaton (1996). "New Kid in Town: Social Capital and the Life Course Effects of Family Migration on Children." American Sociological Review, 61, $368-85$.

Hanushek, Eric (2003). “The Failure of Input-Based Schooling Policies.” Economic Journal, 113, F64-F98.

Hanushek, Eric, John Kain, and Steven Rivkin (2004). "Disruption versus Tiebout Improvement: The Costs and Benefits of Switching Schools." Journal of Public Economics, 88, 1721-1746.

Hanushek, Eric and Steven Rivkin (2012). "The Distribution of Teacher Quality and Implications for Policy." Annual Review of Economics, 4, 131-157. 
Hilber, Christian A.L. (2010). "New Housing Supply and the Dilution of Social Capital." Journal of Urban Economics, 67, 419-437.

Holmlund, Helena, Sandra McNally, and Martina Viarengo (2010). "Does Money Matter for Schools?" Economics of Education Review, 29, 1154-1164.

Huckman, R. and J. Barro (2005). "Cohort Turnover and Productivity: The July Phenomenon in Teaching Hospitals.” NBER Discussion Paper 11182.

Imberman, Scott A. and Michael F. Lovenheim (2015). "Incentive Strength and Teacher Productivity: Evidence from a Group-Based Teacher Incentive Pay System." Review of Economics and Statistics, 97, 364-386.

Jacobs, Jane (1961). The Death and Life of Great American Cities. Random House, New York.

Jovanovic, Boyan (1979). "Job Matching and the Theory of Turnover." Journal of Political Economy, 87, 972-990.

Kaplan, Steven N. and Bernadette Minton (2006). "How has CEO Turnover Changed? Increasingly Performance Sensitive Boards and Increasingly Uneasy CEOs.” NBER Discussion Paper 12465.

Kling, Jeffrey R., Jeffrey B. Liebman, and Lawrence F. Katz (2007). "Experimental Analysis of Neighborhood Effects." Econometrica, 75, 83-119.

Kling, J. Jeffrey, Jens Ludwig, and Lawrence F. Katz (2005). "Neighborhood Effects on Crime for Female and Male Youth: Evidence from a Randomized Housing Voucher Experiment." Quarterly Journal of Economics, 120, 87-130.

Lavy, Victor (2009). "Performance Pay and Teachers' Effort, Productivity and Grading Ethics." American Economic Review, 99(5), 1979-2011.

Lavy, Victor and Edith Sand (2012). "The Friends Factor: How Students' Social Networks Affect their Academic Achievement and Well-Being?" NBER Working Paper 18430.

Lavy, Victor, Silva Olmo, and Weinhardt Felix (2012). "The Good, the Bad, and the Average: Evidence on Ability Peer Effects in Schools." Journal of Labor Economics, 30, 367-414.

Levine, John M. and Hoon Seok Choi (2004). "Impact of Personnel Turnover on Performance and Cognition." In Team Cognition: Understanding the Factors that Drive Process and Performance, Vol. XI, edited by Eduardo Salas and Stephen M. Fiore. American Psychological Association, Washington DC, pp. 153-176.

Levine, John M. and Michael A. Hogg (2010). Encyclopaedia of Group Processes and Interaction Relations. SAGE Publications, London, UK.

Lupton, Ruth (2001). "Places Apart? The Initial Report of CASE's Areas Study." CASE Discussion Paper 14.

Ly, Son Thierry and Arnaud Riegert (2014). Persistent Classmates: How Familiarity with Peers Protects from Disruptive School Transitions." Working paper. Paris School of Economics.

Machin, Stephen, Shqiponja Telhaj, and Joan Wilson (2006). "The Mobility of English School Children." Fiscal Studies, 27, 253-280.

Manski, Charles F. (2000). "Economic Analysis of Social Interactions." Journal of Economic Perspectives, 14, 115-136.

Nicoletti, Cheti and Birgitta Rabe (2014). "The Effect of School Spending on Student Achievement: Causal Relationship or Unobserved Heterogeneity?" Working paper. University of Essex.

Partridge, Mark D., Dan S. Rickman, M. Rose Olfert, and Kamar Ali (2012). "Dwindling U.S. Internal Migration: Evidence of a Spatial Equilibrium or Structural Shifts in Local Labor Markets?" Regional Science and Urban Economics, 42, 375-388.

Pettit, Becky and Sarah A McClanahan (2003). "Residential Mobility and children's Social Capital: Evidence from an Experiment." Social Science Quarterly, 84, 632-649.

Pribesh, Shana and Douglas B Downey (1999). "Why are Residential and School Moves Associated with Poor School Performance?" Demography, 36, 521-534.

Roseth, Carey J., David W. Johnson, and Roger T. Johnson (2008). "Promoting Early Adolescents' Achievements and Peer Relationships: The Effects of Cooperative, Competitive and Individualistic Goal Structures." Psychological Bulletin, 134, 223-246.

Sampson, Robert and W. Byron Groves (1989). "Community Structure and Crime: Testing SocialDisorganization Theory." American Journal of Sociology, 94, 774-802.

Sanbonmatsu, Lisa, Jeffrey R Kling, Greg J. Duncan, and Jeanne Brooks-Gunn, J. (2006). 
"Neighborhoods and Academic Achievement: Results from the Moving to Opportunity Experiment." Journal of Human Resources, 41, 649-691.

Schwartz, Amy, Leanna Stiefel, and Luis Chalico (2009). "The Multiple Dimensions of Student Mobility and Implications for Academic Performance: Evidence from New York City Elementary and Middle School Students." Condition Report. Education Finance Research Consortium, New York State Education Department.

Shaw, Clifford and Henry H. McKay (1969). Juvenile "Delinquency and Urban Areas." University of Chicago Press.

Sjaastad, Larry A. (1962). "The Costs and Returns of Human Migration." Journal of Political Economy, 70, 80-89.

Sutherland, Edwin H. (1934). Principles of Criminology. J. B. Lippincott, Chicago.

Tiebout, Charles M. (1956). A Pure Theory of Local Expenditures.” Journal of Political Economy, 64, 416-424.

Weinhardt, Felix (2014). "Social Housing, Neighborhood Quality and Student Performance." Journal of Urban Economic, 82, 12-31.

Wentzel, Kathryn R. (1993). "Does Being Good Make the Grade? Social Behavior and Academic Competence in Middle School.” Journal of Educational Psychology, 85, 357-364.

\section{Supplementary Data}

Supplementary data are available at JEEA online. 